\title{
Complex frictional analysis of self-lubricant W-S-C/Cr coating
}

Tomas Polcar ${ }^{\mathrm{a}}$, Fredrik Gustavsson ${ }^{\mathrm{b}}$, Thomas Thersleff ${ }^{\mathrm{b}}$, Staffan Jacobson ${ }^{\mathrm{b}}$, A. Cavaleiro $^{\mathrm{c}}$

a) Department of Control Engineering, Faculty of Electrical Engineering, Czech Technical University in Prague, Technická 2, Prague 6, Czech Republic

b) Applied materials Science, Department of Engineering Sciences, Uppsala University, Box 534, 75121 Uppsala, Sweden

c) SEG-CEMUC - Department of Mechanical Engineering, University of Coimbra, Rua Luís Reis Santos, P-3030 788 Coimbra, Portugal

\section{Corresponding author:}

T. Polcar: Tel: +420 22435 7598; polcar@fel.cvut.cz

\begin{abstract}
Transition metal dichalcogenides belong to one of the most developed class of materials for solid lubrication. However, one of the main drawbacks of most of the self-lubricating coatings is their low load-bearing capacity, particularly in terrestrial atmospheres. In our previous works, alloying thin films based on tungsten disulfide with non-metallic interstitial elements, such as carbon or nitrogen, has been studied in order to improve tribological performance in different environments. Excellent results were reached with the deposited coatings hardness, in some cases, more than one order of magnitude higher than single W-S films.
\end{abstract}


In this work, W-S-C films were deposited with increasing $\mathrm{Cr}$ contents by co-sputtering chromium and composite $\mathrm{WS}_{2}-\mathrm{C}$ and targets. Two films were prepared with approx. 7 and 13 at.\% of $\mathrm{Cr}$. Alloying with chromium led to dense films with amorphous microstructure; the hardness and adhesion was improved. Sliding tests were carried out in dry and humid air using pin-on-disc with $100 \mathrm{Cr} 6$ steel ball as a counterpart. To analyse the sliding process, the surfaces in the contact were investigated by X-ray photoelectron spectroscopy (bonding), scanning electron microscopy (SEM), transmission electron microscopy (TEM), and Raman spectroscopy (TEM). Surface and sub-surface structural modification of the coating and composition of the transferred tribolayer are discussed in detail. High friction in humid air was attributed to the absence of well-ordered $\mathrm{WS}_{2}$ sliding interface. On the other hand, the existence of such interface explained a very low friction observed in dry air.

\section{Introduction}

Transition metal dichalcogenides (TMD), namely molybdenum and tungsten disulfides and diselenides, exist in two crystal forms, hexagonal and rhombohedral. Only the hexagonal structure will be discussed, since it is the most common and important for low-friction applications. The hexagonal crystal structure with six-fold symmetry exhibits a laminar structure. Each chalcogenide atom is equidistant from three metal atoms, end each metal atom is equidistant from six chalcogenide atoms. Large spacing between X-M-X (X - chalcogenide, $\mathrm{M}$ - transition metal) layers and weak Van der Waals forces may facilitate easy inter or intra-crystalline slip [1,2]. Despite contradictory reports, it seems that there is no fundamental difference between interfacial and intercrystalline friction of TMD. Strong intra-planar covalent bonding helps resist asperity penetration even under extremely high contact pressures. Thanks to layered structure, the properties of TMD are highly anisotropic [1].

The inter-lamellar bonding within a TMD crystal is at a minimum and the presence of contaminants thus hinders lubrication properties due to increasing inter-lamellar interaction []. Thus, TMD 
fundamentally differ of other well-known layered materials such as mica or graphite with strong ionic bonding. To decrease friction of graphite, the bond energies must be reduced by the presence of contaminants, typically water vapor [3]. As a result, the friction of graphite in dry ambient or vacuum is high, whereas TMD exhibits higher friction in humid atmosphere.

TMD are extensively used as solid lubricants as oil additives or thin films. The most convenient method to prepare these films is magnetron sputtering; thus, all references hereinafter deals with coatings deposited by this method. Sputtered $\mathrm{MoS}_{2}$ coatings, the most known member of TMD family, were thoroughly analyzed in 80 's and 90's. The first studies on the deposition of $\mathrm{MoS}_{2}$ leaded usually to films with columnar morphologies with very high porosity and consequent very low values in hardness [4]; the adhesion to the steel substrates was limited and the coatings deteriorated in the presence of humid air. Thus, their tribological behavior was unsuitable whenever high loads were applied to the sliding contact or tests were carried out in moisture containing atmospheres. Other transition metal dichalcogenides have similar properties to those of molybdenum disulfide, although diselenides exhibited improved resistance to water in relation to sulfides $[1,5]$.

Despite mentioned differences among pure TMD coatings, their common drawbacks are a very low load-bearing capacity, a low adhesion to the substrate and a detrimental effect of the air moisture in the tribological contact. There are many different possibilities to improve the tribological behavior of these coatings. One of the most successful way is to deposit a composite material associating high strength materials with self-lubricants, i.e. doping of TMD film by other metals being titanium the most successful $[6,7]$.

Voevodin et al. [8] and later Cavaleiro et al. [9] alloyed $\mathrm{WS}_{2}$ with carbon and prepared nanocomposite coating combining small hard $\mathrm{WC}$ and lubricant $\mathrm{WS}_{2}$ nanograins embedded in an amorphous carbon matrix. The core idea behind this concept was to combine excellent tribological properties of DLC films in humid air and extremely low friction of $\mathrm{WS}_{2}$ phase in dry air or vacuum. The coatings were hard (about $10 \mathrm{GPa}$ ) and exhibited excellent tribological properties in nitrogen. 
In humid air, carbon matrix protected $\mathrm{WS}_{2}$ phase and the coating endurance was increased; however, the friction in humid air was still very high.

Recently we developed a novel class of self-lubricant coatings with oriented separated TMD platelets randomly dispersed in an amorphous carbon matrix $[10,11]$. This microstructure allowed structural adaptation of the coating material. We observed formation of a thin TMD sliding interface; moreover, the coating below this interface was modified and TMD platelets were reoriented inside the carbon matrix. As a result, the sensitivity of the friction to air humidity significantly decreased [11]. However, the nanostructure referred to above led to a lower hardness values (approximately $5 \mathrm{GPa}$ for WSC coatings), which limited abrasion resistance and use of these coatings on rougher substrates. Alloying of WSC coating with metals could lead to improve mechanical properties and adhesion of the films on steel substrates; moreover, it is possible to tune coating microstructure by metal content.

The aim of this study is to analyze the effect of the chromium on the microstructure, mechanical and, particularly, tribological properties of WSC-Cr coatings.

\section{Experimental details}

The WSC-Cr films were deposited using an r.f. magnetron sputtering chamber. Prior to the coating deposition, the substrates were cleaned by establishing the plasma close to the substrates electrode for 20 minutes. Two targets were used to deposit WSC-Cr coatings: pure chromium target and graphite target with $\mathrm{WS}_{2}$ pellets placed on the erosion zone. The number of pellets was calculated to obtain approx. 40 at.\% of carbon in the WSC film (i.e. the film without co-sputtered chromium). To improve coating adhesion, pure chromium interlayer was deposited on the substrates. The power applied to the $\mathrm{C}$ target was kept constant, whereas power of $\mathrm{Cr}$ target varied to obtain different chromium content in the coatings.

The chemical composition of the coatings was evaluated by electron probe microanalysis (EPMA). 
Hardness values were determined by depth-sensing indentation technique [12], and adhesion was evaluated by progressive load scratch tests. The chemical bonding of the films was analyzed by Raman spectroscopy (DPSS laser, wavelength $532 \mathrm{~nm}$, and Ar laser, wavelength $514.5 \mathrm{~nm}$ ), Fourier-transform infrared spectroscopy (FTIR) and X-ray photoelectron spectroscopy (XPS; Mg $\mathrm{K} \alpha$ radiation). The structure was analyzed by $\mathrm{X}$-ray diffraction (Co $\mathrm{K} \alpha$ radiation) and by transmission electron microscopy (TEM), the morphology and film cross-section was investigated by scanning electron microscopy (SEM).

Two sets of tribological measurements were carried out. The first one was performed exclusively in humid air (relative humidity 34-45\%) using a pin-on-disk tribometer with 100Cr6 balls with a diameter of $6 \mathrm{~mm}$ as static partners. Different contact loads, between 1 and $15 \mathrm{~N}$, were applied; the test duration was 5000 laps. The second set used similar pin-on-disc tribometer; however, the load was $10 \mathrm{~N}$, the test duration 10000 laps, and the testing ambient was dry (relative humidity approx. $1 \%$ ) humid air (relative humidity approx. 55\%). The friction coefficient values presented in this work are the average values for the entire test, unless noted otherwise. Wear rates of the coatings and of the balls were determined as worn volume (measured by $3 \mathrm{D}$ white light profilometer) per sliding distance per load.

Special attention was paid to analyze the worn surfaces and the wear debris particles. The worn surfaces were observed by SEM coupled with energy dispersive X-ray spectroscopy (EDS) and characterized by Raman spectroscopy. Selected parts of the wear tracks and the tribofilms formed on the ball surfaces were examined by TEM; the TEM cross sections were prepared by using a FEI Strata DB235 Focused Ion Beam instrument. The samples were taken out by in-situ lift out with an Omniprobe $\mathrm{W}$ needle and transferred to a $\mathrm{Cu}$-grid and then thinned down to $<50 \mathrm{~nm}$ thickness. As a final step, the samples were fine polished using low energetic ions to reduce the amount of surface damage. The samples were then analyzed in a FEI Tecnai F30 ST at $300 \mathrm{kV}$, equipped with a Gatan Imaging Filter which was used for EELS analysis to identify the chemical composition of the tribofilms. 


\section{Results}

\subsection{Coating characterization}

\subsubsection{Chemical composition}

The deposition power ratio $P_{C r} / P_{C+W S 2}$ of the targets was varied between 0 and 0.13 , resulting in different $\mathrm{Cr}$ contents in the films. The coatings consisted of an approximately $300 \mathrm{~nm}$ thick pure chromium interlayer and functional WSC-Cr film with a thickness in the range from 1.7 to 2.7 micrometers. The thicknesses were measured on broken coated silicon wafer by SEM. The thicknesses were measured in SEM on the cross sections produced by breaking the coated silicon wafers. The coating cross-section (not shown) was featureless, showing no evidence of columnar structure, pores or voids. Table 1 summarizes the targets powers and corresponding chemical composition. Some depositions were repeated to obtain a large set of samples for tribological tests (identical depositions are denominated as A, B, etc). Chemical composition measured by EPMA demonstrated the repeatability of the process. EPMA analysis of the chemical composition demonstrated that the process was highly repeatable. The composition was also measured with XPS to confirm the EPMA result, since both methods have several limitations. The penetration depth of EPMA is about 2 microns and thus the detection of the interlayer could overestimate the $\mathrm{Cr}$ content in the film. This is clearly demonstrated in the case of WSC film, where the chromium detected originated exclusively from the interlayer. XPS spectra were taken after etching some $5 \mathrm{~nm}$ of the film to reduce the effect of contamination. However, etching typically leads to preferential removal of sulfur, which results in lower measured sulfur content [13]. The oxygen content followed the same trend for both methods, i.e. it increases with increasing $\mathrm{Cr}$ content. The lower oxygen values measured with XPS could indicate that the $\mathrm{O}$ concentration is lower close to the surface. It could be expected, since initial oxygen contamination of targets (note that carbon target and $\mathrm{WS}_{2}$ pellets are porous compared to metallic targets) is reduced during deposition process. 
To facilitate reading, we denominate coatings as WSC-Cr0 (the film sputtered without chromium deposition 1), WSC-Cr7 (depositions 2-A, 2-B) and WSC-Cr13 (depositions 3-A, 3-B, 3-C).

Table 1 Critical load, hardness and chemical composition measured by EPMA and XPS. The latter was measured at a depth of approximately $5 \mathrm{~nm}$.

\begin{tabular}{|c|c|c|c|c|c|c|c|c|c|c|c|c|c|c|}
\hline Deposition & $\mathrm{P}\left[\mathrm{C}+\mathrm{WS}_{2}\right]$ & $\mathrm{P}[\mathrm{Cr}]$ & Chemic & a comp & osition & at.\% - & PMA) & Chem & al cor & Dositio & (at.\% & XPS) & Hardness & Critical \\
\hline & (W) & (W) & W & $S$ & C & $\mathrm{Cr}$ & $\mathrm{O}$ & W & $S$ & $\mathrm{C}$ & $\mathrm{Cr}$ & $\mathrm{O}$ & (GPa) & $\operatorname{load}(\mathrm{N})$ \\
\hline 1 & 600 & 0 & 23.6 & 29.8 & 42.0 & 0.6 & 4.2 & 38.7 & 20.0 & 40.0 & 0.0 & 1.3 & $4.9 \pm 0.2$ & 12 \\
\hline $2-\mathrm{A}$ & 600 & 50 & 20.3 & 25.1 & 40.4 & 7.0 & 7.2 & 34.0 & 20.5 & 33.4 & 6.8 & 5.3 & $5.5 \pm 0.2$ & \\
\hline $2-B$ & 600 & 50 & 19.1 & 26.6 & 38.1 & 7.1 & 9.1 & & & & & & $6.2 \pm 0.4$ & 16 \\
\hline $3-\mathrm{A}$ & 600 & 76 & 17.4 & 23.1 & 37.6 & 13.4 & 8.5 & 32.0 & 17.0 & 33.1 & 12.0 & 5.9 & $6.4 \pm 0.3$ & \\
\hline $3-B$ & 600 & 76 & 18.5 & 24.1 & 35.8 & 13.5 & 8.1 & & & & & & $7.1 \pm 0.3$ & 19 \\
\hline $3-\mathrm{C}$ & 600 & 76 & 18.2 & 22.4 & 38.1 & 13.5 & 7.8 & & & & & & & 23 \\
\hline
\end{tabular}

\subsubsection{Chemical bonding and microstructure}

XPS was acquired first on the as-deposited surfaces showing mainly tungsten and chromium oxide, and then again after 48 seconds of sputter cleaning, reaching a depth of approximately $5 \mathrm{~nm}$. The characteristic W4f XPS spectra of WSC-Cr films shown in Fig. 1 are deconvoluted to display the contributions from different types of bonds. We detected following bonds (in brackets their nominal position according to [14]): $\mathrm{W}-\mathrm{C}(31.5-32.2 \mathrm{eV}) ; \mathrm{WO}_{3} 35.2-36.6(\mathrm{eV})$ and $\mathrm{WS}_{2}(31.6-33.2 \mathrm{eV})$ bonds. The peaks corresponding to later bond were found to be positioned in lower binding energies than the $\mathrm{W}-\mathrm{S}$ contribution, which is in a good agreement with the lower electronegativity of carbon compared to sulfur [9]. In fact, a reasonable fit could be achieved even without $\mathrm{W}-\mathrm{C}$ peaks. However, such deconvolution would not satisfy the conditions suggested in Ref [14] that more peaks are required for a chi-squared value greater than four. The $\mathrm{C} 1 \mathrm{~s}$ spectrum showed both C-C and W-C bonds, whereas S2p was identified as a combination of W-S bond and a minor peak representing S-O bond.

The Cr2p region of the XPS spectra showed a pair of peaks at 574.4 and $\sim 583.7 \mathrm{eV}$ close to the position of metallic $\mathrm{Cr}$ (574.1 and $583.4 \mathrm{eV}$ [14]). The broad elevation at approximately 590-602 $\mathrm{eV}$ was attributed to satellite peaks [15]. The peak separation ruled out contribution of $\mathrm{Cr}_{2} \mathrm{O}_{3}$ with a 
pair of peaks at binding energies $\left(9.3 \mathrm{eV}\right.$ for metallic $\mathrm{Cr}, 9.7 \mathrm{eV}$ for $\mathrm{Cr}_{2} \mathrm{O}_{3}$ ) clearly indicate metallic chromium or chromium carbide. It is possible, however, that very weak peaks at the positions associated with $\mathrm{Cr}_{2} \mathrm{O}_{3}(576.6$ and $586.3 \mathrm{eV})$ were present and contributed minimally to the spectra. However, the position of $\mathrm{Cr} 2 \mathrm{p}$ peaks is also very close to the ones characteristic of $\mathrm{Cr}-\mathrm{S}, \mathrm{Cr}-\mathrm{C}$ and $\mathrm{Cr}-\mathrm{W}$ which does not rule out the possibility of having $\mathrm{Cr}$ bonded to those elements, particularly when considering amorphous nature of the films. Nevertheless, W4f, C1s and S2p spectra of all coatings were almost identical; thus, the alloying of WSC film with chromium did not change the bonding state of the film.

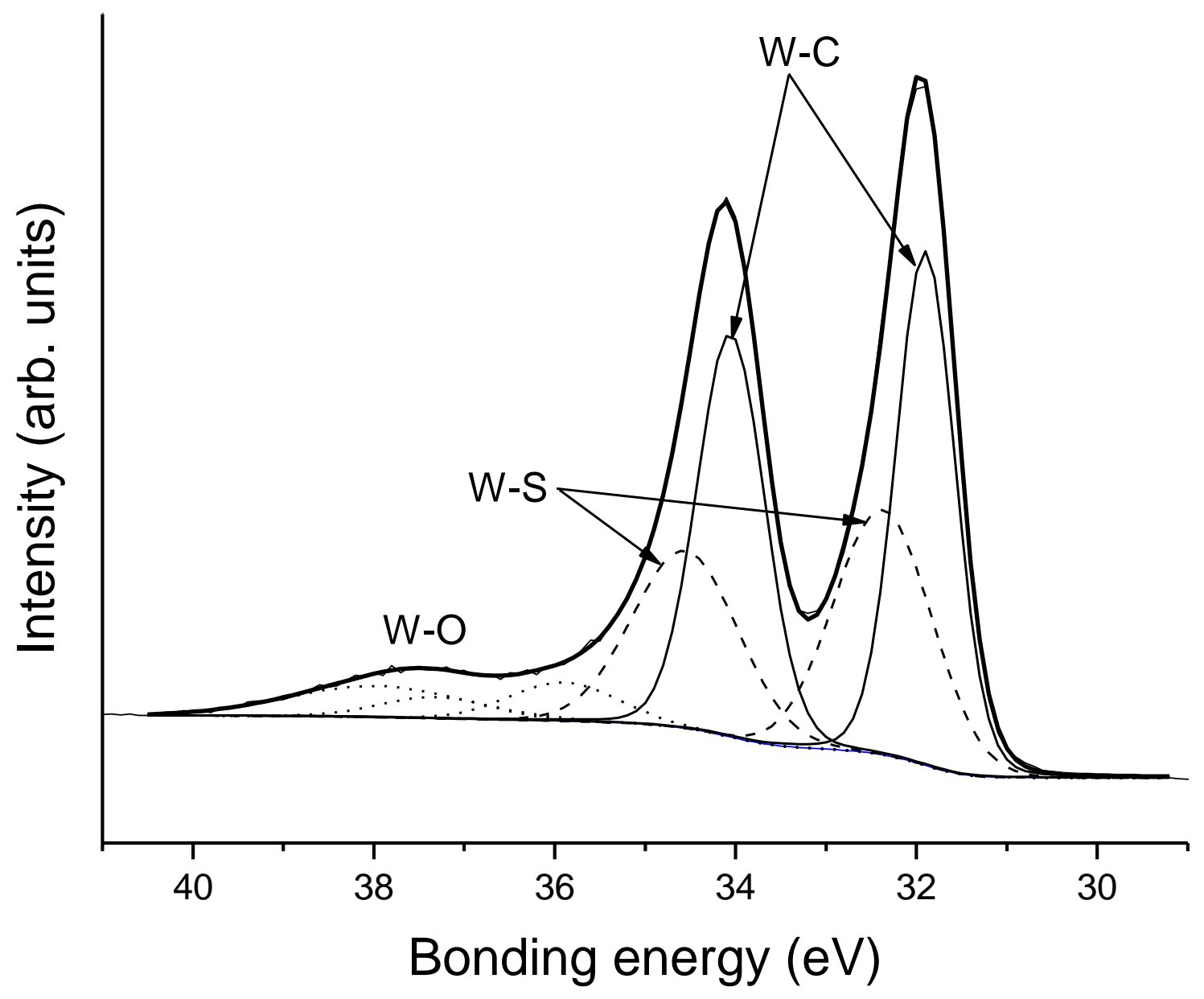

Fig. 1 W4f XPS spectrum of WSC-Cr13 film (approx. depth $5 \mathrm{~nm}$ )

The WSC-Cr0 coating was investigated by TEM in our previous study, where it was shown to 
involve randomly oriented WS2 platelets embedded into a carbon matrix [16]. TEM analysis of Crdoped films showed amorphous-like microstructure, see Fig. 2. XRD patterns were characteristic of amorphous material and thus confirmed TEM observations (not shown).

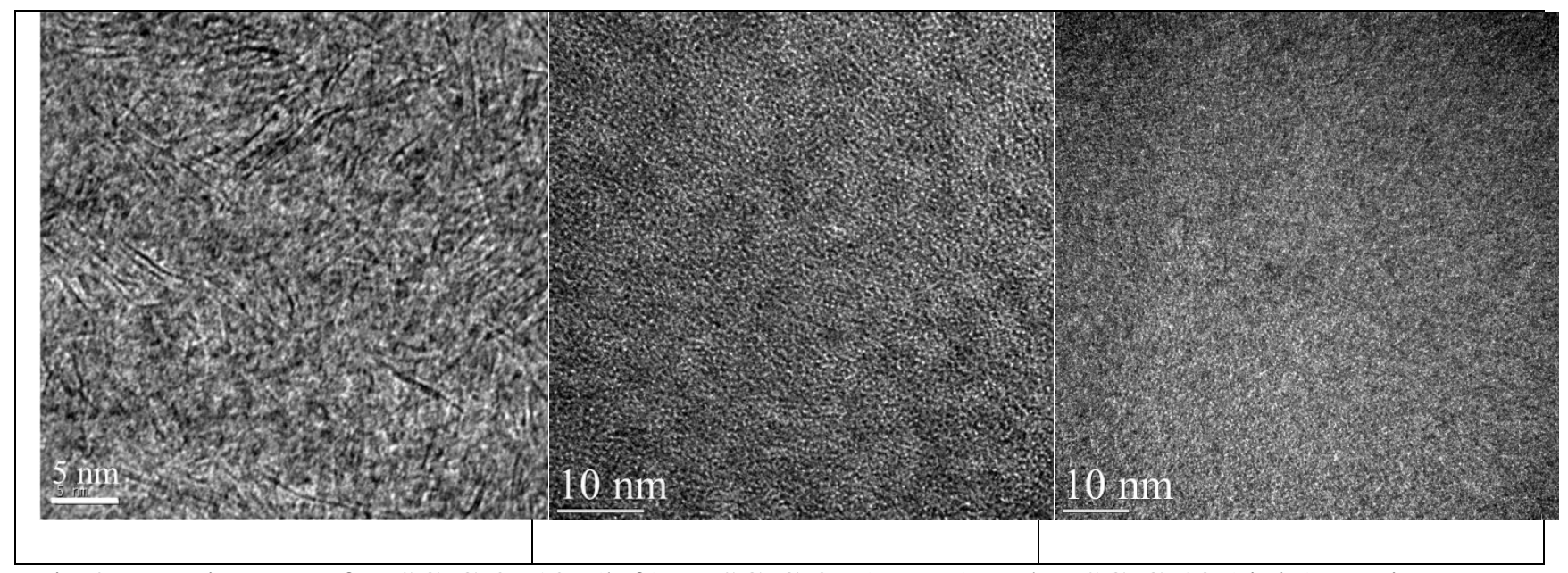

Fig 2 TEM images of WSC-Cr0 [10] (left), WSC-Cr07 (centre) and WSC-Cr13 (right) coatings.

The analysis of FTIR spectra (not shown) was difficult due to a very noisy background. Only one region, 900 to $1300 \mathrm{~cm}^{-1}$, was clearly distinguishable from the background. Two prominent peaks at approximately 980 and $1260 \mathrm{~cm}^{-1}$ together with a barely visible peak at approximately $1140 \mathrm{~cm}^{-1}$, are similar to tungsten bonded to carbon [17]. However, peaks at 1079 and $983 \mathrm{~cm}^{-1}$, as well as the broad band from 500 to $1000 \mathrm{~cm}^{-1}$, are associated with $\mathrm{W}-\mathrm{O}$ bonds and thus makes it very difficult to distinguish tungsten oxides and carbides [18]. We could identify a sharp valley at $1633 \mathrm{~cm}^{-1}$ as $\mathrm{WS}_{2}$, although the signal in the $1400-1800 \mathrm{~cm}^{-1}$ region was particularly noisy. The same reason hinders the identification of possible $\mathrm{Cr}_{2} \mathrm{O}_{3}$ peaks that should appear at 1450 and $1490 \mathrm{~cm}^{-1}$ [19] as well as $\mathrm{C}-\mathrm{C}$ bonds at $1640 \mathrm{~cm}^{-1}[20]$.

Raman spectroscopy is a very sensitive method for the chemical identification and the structural analysis of WS2 and carbon. $2 \mathrm{H}-\mathrm{WS}_{2}$ single crystals have 4 Raman active crystal vibrations at the G-point of the reciprocal unit cell: $A_{1 \mathrm{~g}}\left(421 \mathrm{~cm}^{-1}\right), \mathrm{E}_{2 \mathrm{~g}}{ }^{(1)}\left(356 \mathrm{~cm}^{-1}\right), \mathrm{E}_{1 \mathrm{~g}}\left(306 \mathrm{~cm}^{-1}\right)$, and $\mathrm{E}_{2 \mathrm{~g}}{ }^{(2)}$ (27 $\mathrm{cm}^{-1}$ ). Carbon-based sputtered coatings exhibit two major peaks (D and G) in the range 1100-1700 $\mathrm{cm}^{-1}$. Fig. 3 shows Raman spectra of as deposited WSC-Cr coatings. The broad peaks close to the $\mathrm{WS}_{2}$ position were distinct in the case of WSC-Cr0. On the other hand, only vestiges of $\mathrm{WS}_{2}$-related 
peaks were observed for the Cr-containing coatings. The broadening of the $\mathrm{WS}_{2}$ Raman modes is related to the presence of structural defects and / or stress gradients in the scattering volume [21]. Therefore, the broad $\mathrm{WS}_{2}$-related peaks indicated low structural quality of the $\mathrm{WS}_{2}$ phase in the WSC-Cr0 coating and an amorphous nature of the chromium-containing coatings and thus corroborated TEM observations. Since $\mathrm{Cr}_{2} \mathrm{O}_{3}$ shows a pair of peaks at 305 and $350 \mathrm{~cm}^{-1}$ [22,23], i.e. in similar positions to that of $\mathrm{WS}_{2}$, they might overlap with $\mathrm{WS}_{2}$ peaks. However, we do not expect significant contribution of $\mathrm{Cr}_{2} \mathrm{O}_{3}$ due to either the low oxygen content in the film or the absence both $\mathrm{Cr}_{2} \mathrm{O}_{3}$ Raman peak at $\sim 550 \mathrm{~cm}^{-1}$ [24] and $\mathrm{Cr}-\mathrm{O}$ bond detected by XPS (see above). The existence of carbon D and G bands corroborates the XPS results (C1s peak analysis), although it is difficult to estimate the fraction of free carbon and carbides in the films. We observed an increase in $\mathrm{I}(\mathrm{D}) / \mathrm{I}(\mathrm{G})$ ratio when $\mathrm{Cr}$ was added into films. The higher $\mathrm{I}(\mathrm{D}) / \mathrm{I}(\mathrm{G})$ ratio is usually attributed to an increase in number and/or size of the graphitic domains [25] and it is in accordance with results on Cr-doped DLC coatings [26].

It should be noted that the power of laser had to be kept very low to avoid film damage. Consequently, the spectra were of low quality hindering detailed peak analyses. 


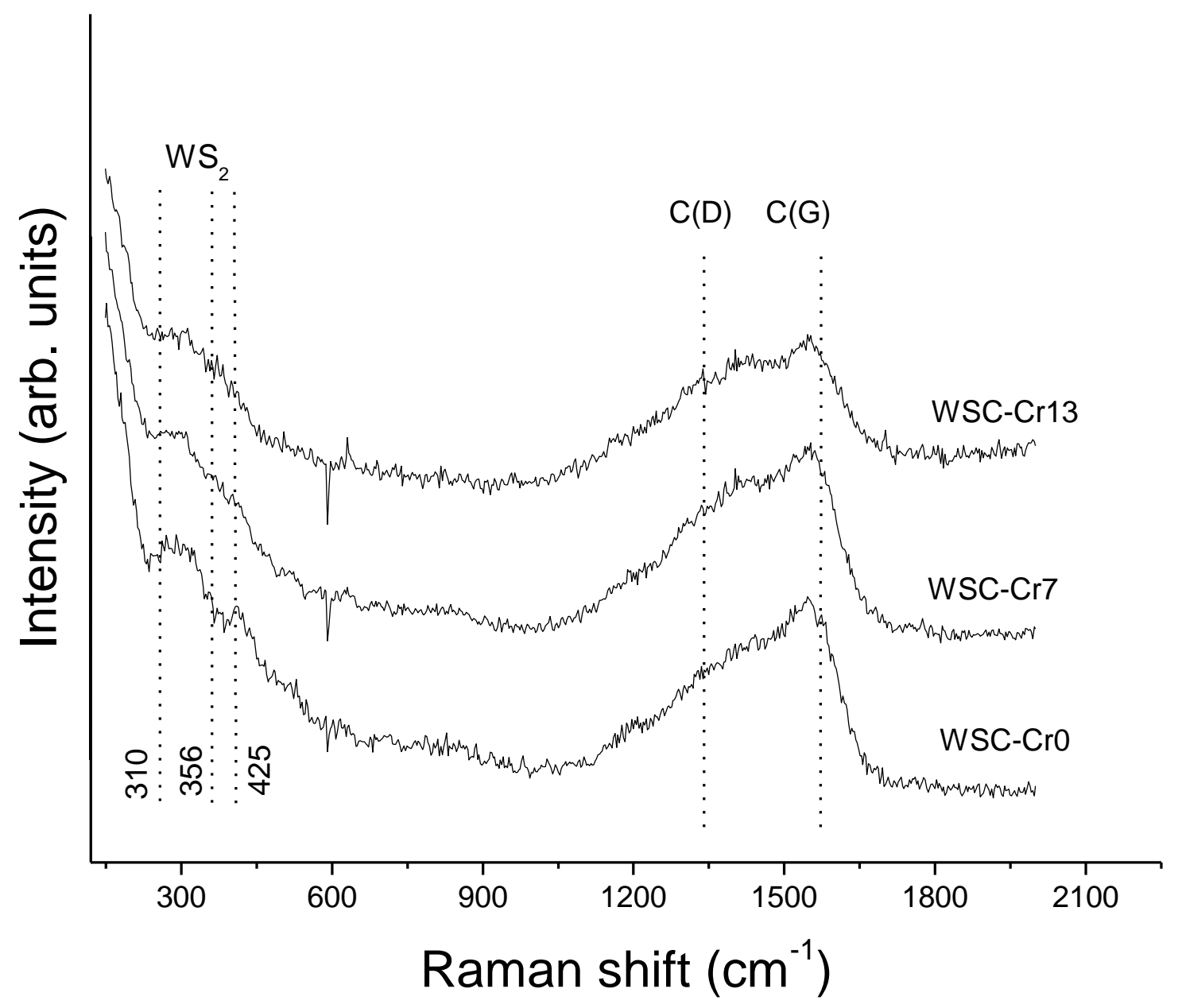

Fig. 3 Raman spectra of as-deposited coatings.

\subsubsection{Adhesion and mechanical properties}

Critical load and thus adhesion of the coating was increased by alloying of WSC coatings with chromium (see Table 1); critical load around $20 \mathrm{~N}$ could be considered as sufficient for sliding applications. Alloying with $\mathrm{Cr}$ increased the coating hardness (Table 1). This trend was observed for co-sputtered $\mathrm{WS}_{2}$ or $\mathrm{MoS}_{2}$ films with metals and explained by reducing the columnar morphology and consequently reducing the number of pores and voids; however, WSC-Cr0 coating was already dense and morphologically featureless (co-deposition with carbon suppressed the columnar growth). As referred to above, $\mathrm{WS}_{2}$ platelets observed in WSC-Cr0 coating could decrease the 
hardness due to easy slip; therefore, alloying of this film with chromium eliminated the formation of $\mathrm{WS}_{2}$ platelets and thus could justify observed increase in hardness. In general, presented films are softer than nanocomposite $\mathrm{WC}_{\mathrm{DLC}} \mathrm{WS}_{2}$ films [8]; on the other hand, the hardness is still significantly higher than that of sputtered $\mathrm{WS}_{2}$ films [10].

\subsubsection{Tribological properties}

Pin-on-disk sliding tests carried out using different loads (from 1 to $15 \mathrm{~N}$ ) for 5000 cycles in humid air showed a decrease in the average friction coefficient with increasing contact load (Fig. 4). This behavior matches with similar doped TMD systems and an indirect indication that a $\mathrm{WS}_{2}$-rich tribolayer was formed on the coating surface and the ball $[10,11]$. In the very first few cycles, the friction coefficient was higher due to polishing of asperities and removal of surface oxidation. After several hundreds of cycles the friction values decreased and a steady-state wear regime was reached. Inset of Fig. 4 shows the initial evolution of the friction. Alloying with $\mathrm{Cr}$ increased the friction coefficient, although it was still much lower than that of pure $\mathrm{WS}_{2}$ coating [16]. It should be noted that the coating with the highest $\mathrm{Cr}$ content exhibited an initial friction coefficient around 0.3; moreover, the wear tracks were deeper showing several scratches parallel to the sliding direction. The shapes of the wear tracks formed on coatings of different compositions in the tests with $5 \mathrm{~N}$ load and 5000 cycles are illustrated in Fig. 5. The wear rates of WSC-Cr0 and WSC-Cr7 were similar and almost independent of the applied load. The wear resistance of WSC-Cr13 was the lowest with the maximum wear track depths around 1.5 micrometer, i.e. approx. $70 \%$ of the functional layer. The ball wear rates were very low, particularly against the WSC-Cr7 film. We carried out as well longer tests to estimate evolution of the ball wear during the sliding tests. The ball wear scars had almost the same dimensions after 5000 and 50000 laps; the coating wear volume increased only about $10 \%$ compared to the 5000 laps test (thus the wear rate calculated as worn volume per load per sliding distance was significantly lower for longer test). Wear results indicated high wear during initial contact (running-in); once steady state was reached, the wear of coatings 
and balls was minimal.

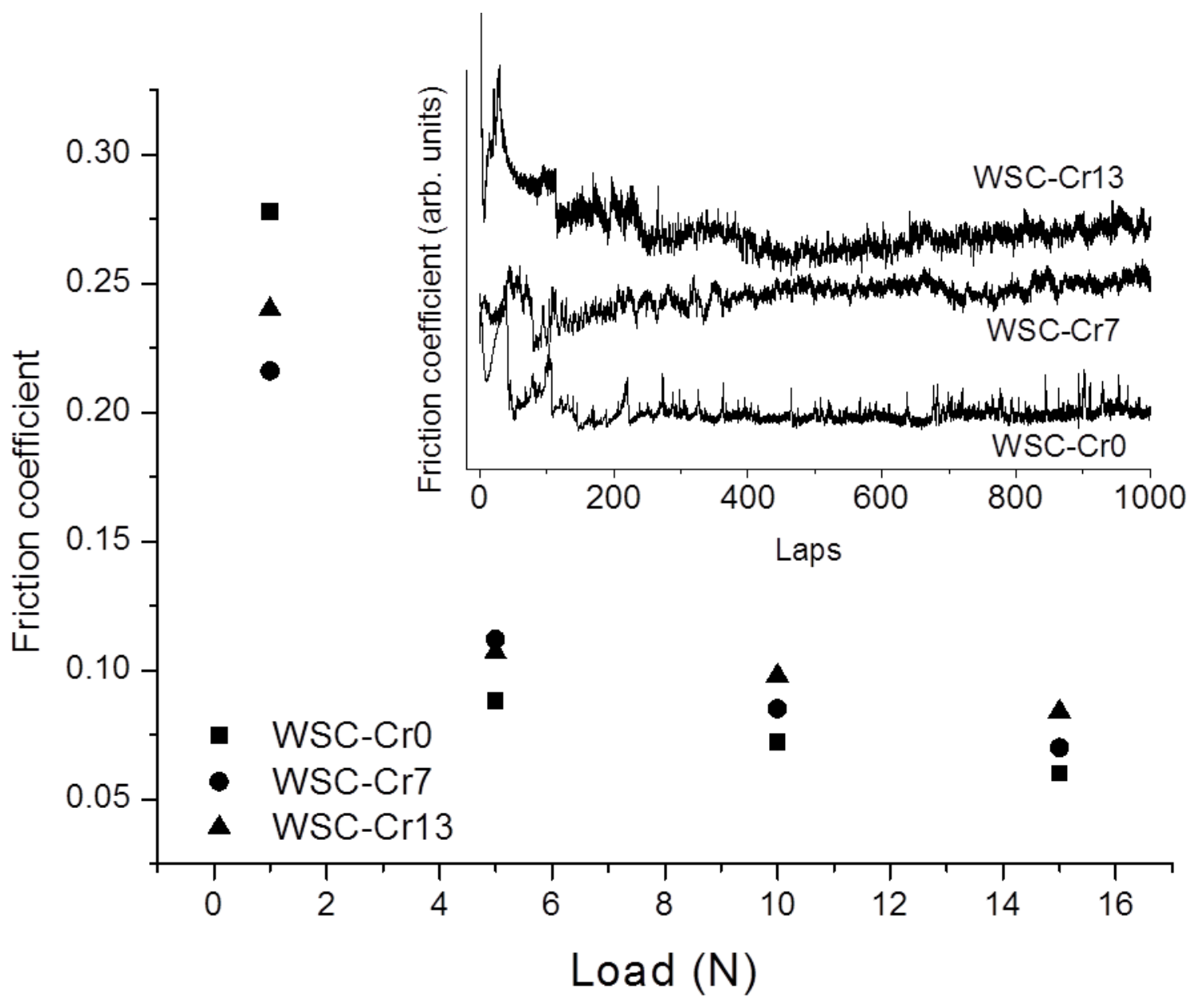

Fig. 4 Friction coefficient vs. applied load. Inset shows initial evolution of friction, load 5 N. The inset shows the evolution of the friction after starting of the tests (running in). 

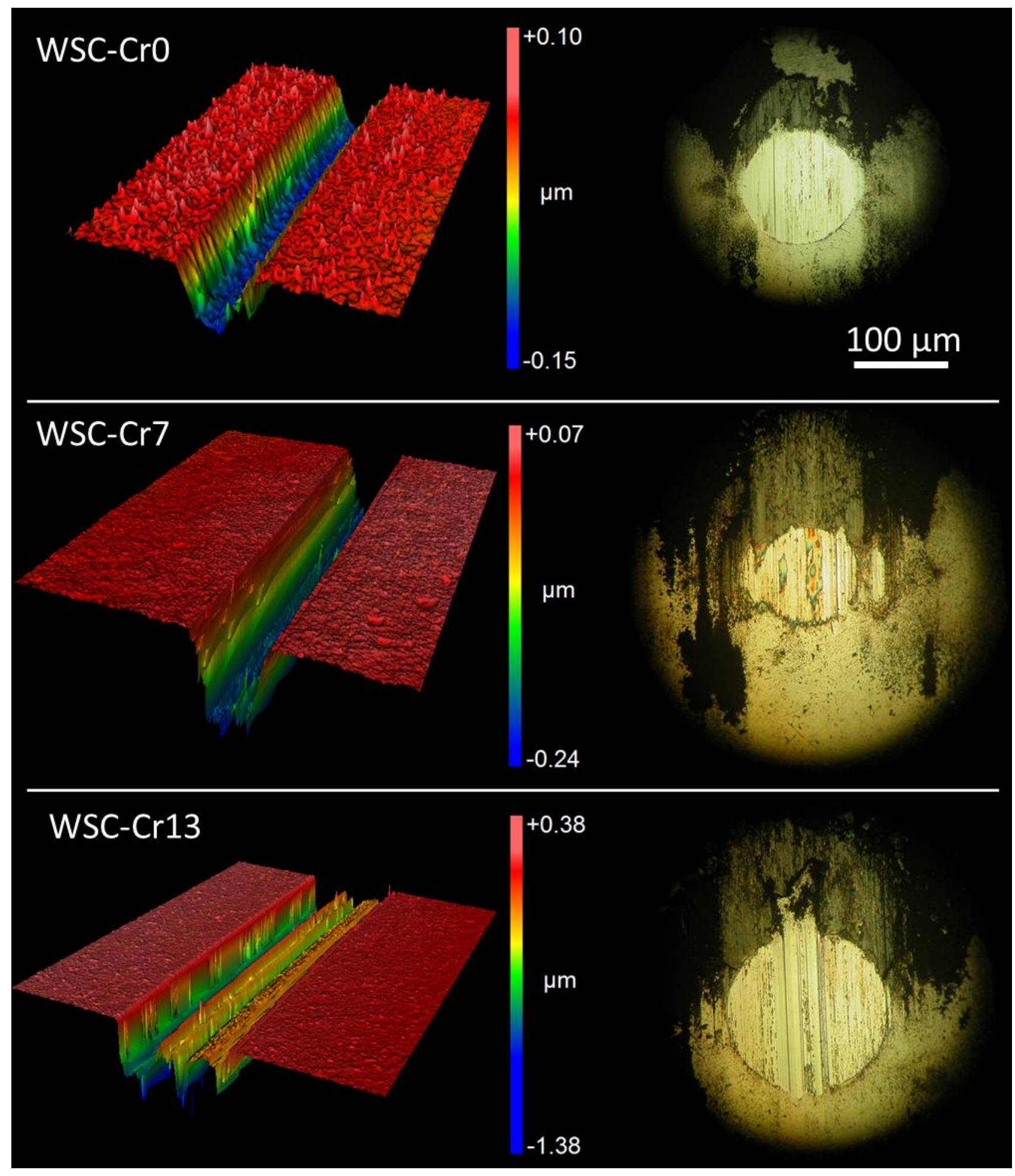

Fig. 5 Shape of the wear tracks on the coated discs (white light interference topography) and optical images of the corresponding wear scars on the balls. Sliding tests with a load of $5 \mathrm{~N}, 5000$ cycles.

Also when sliding in dry air, the initial friction was very high and the running-in periods up towards 2000 cycles. After the running-in, $\mu$ was in the range $0.018-0.025$ (Fig. 6). The main difference 
between the non-doped and Cr-doped films is the running-in stage. For the WSC-Cr0 film the friction rapidly dropped to the low steady state low level while it took much longer for the Cr-doped films. Moreover, the Cr-doped films initially showed a relatively slowly increasing friction before reaching a maximum and falling towards the steady state level.

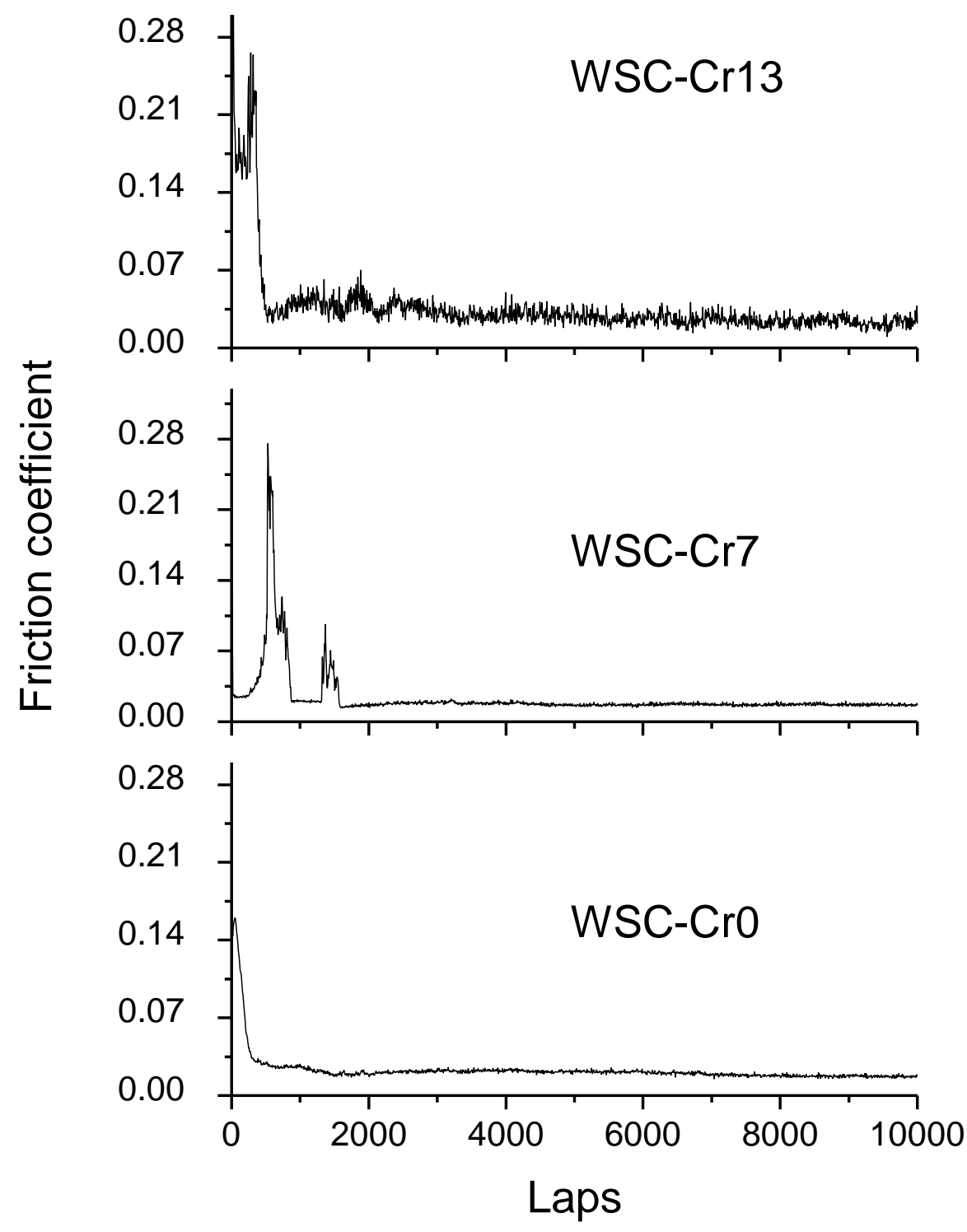

Fig 6 Friction curves of WSC-Cr coatings, sliding in dry air, $10 \mathrm{~N}$ load.

\subsection{Analysis of the worn surfaces}

\subsubsection{Sliding in humid air}

An example of SEM and EDS of the ball wear scar is shown in Fig 7. The tribofilm was apparently 
very thin except of several strips close to the border of the wear scar where it seems thicker. On the other hand, a thick layer of adhered material accumulated in front of the ball wear scar.
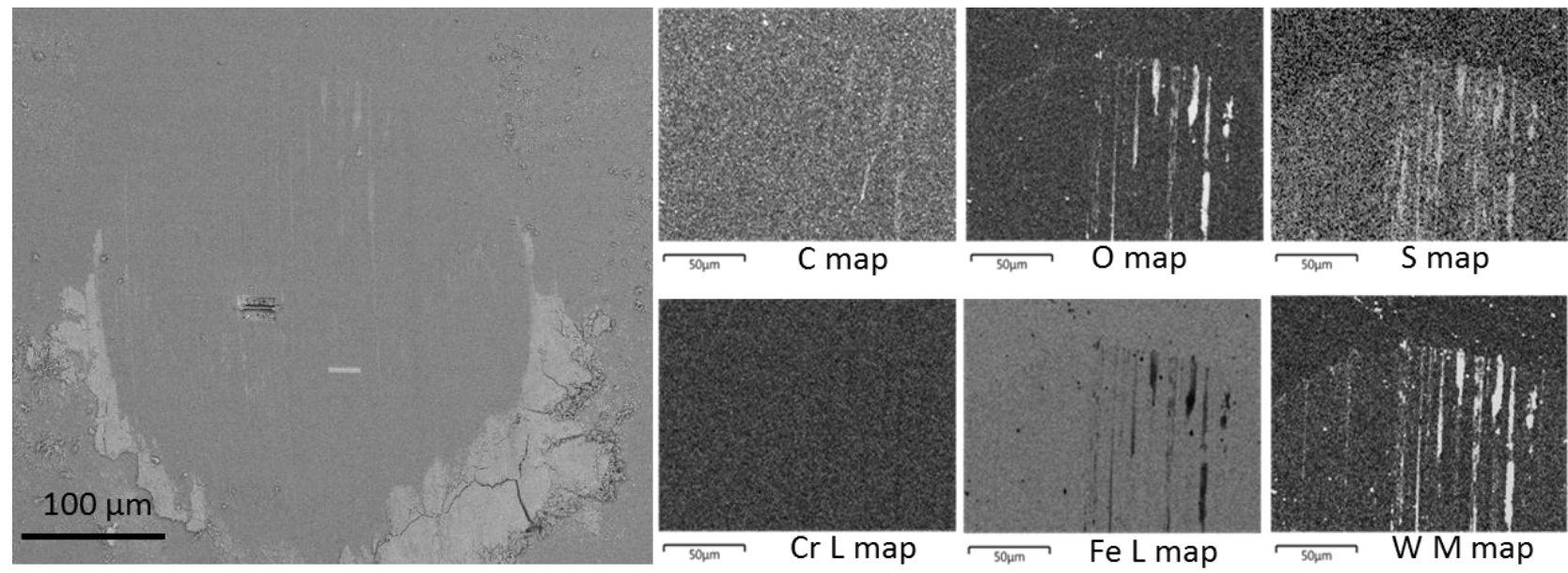

soum $\mathrm{O}$ map

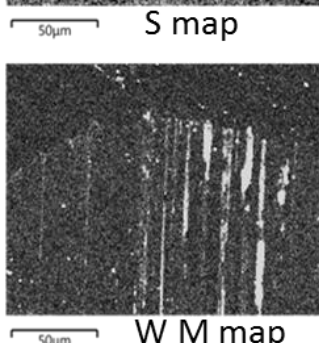

Fig. 7 SEM image of the wear scar on the ball (left) and corresponding EDS qualitative element maps (right) from the test with WSC-Cr7 coating in humid air. Note the FIB cut of the ball tribolayer close to the center of the scar.

Raman analysis of the ball wear scars could shed a light on the structure and composition of the adhered wear debris. The material adhered on the balls could be divided into three groups: a) a very thin layer covering parts of the wear scar; b) wear debris attached in front of the wear scar; and c) wear debris scattered farther on both sides of the wear scar. Fig. 8 shows an example of the Raman spectra acquired from the three positions defined above in the ball wear scars after tests with WSCCr0 and WSC-Cr13 coatings. The debris adhered on the sides of the wear scar (position c) was almost exclusively graphitic carbon; only vestiges of $\mathrm{WS}_{2}$ peaks were observed. Contrastingly, the layer adhered in front of the scar (position b) consisted of graphitic carbon and $\mathrm{WS}_{2}$. Sharp peaks at approximately 310 and $420 \mathrm{~cm}^{-1}$ revealed higher structural order of $\mathrm{WS}_{2}$ phase compared to asdeposited films (see Fig. 3). Spectra taken in positions (b) and (c) were almost identical for all three tested coatings. The tribolayer adhered directly in the ball wear scar was not homogeneous and Raman spectra taken at different spots close to the center could be split into two categories. The first one was characterized by a single large peak around $940 \mathrm{~cm}^{-1}$, which was identified as iron 
oxide; such spectrum was typical of Cr-containing coatings. The second combined iron oxide, $\mathrm{WS}_{2}$ and carbon; it was observed more often on the ball wear scar of WSC-Cr0 coating.

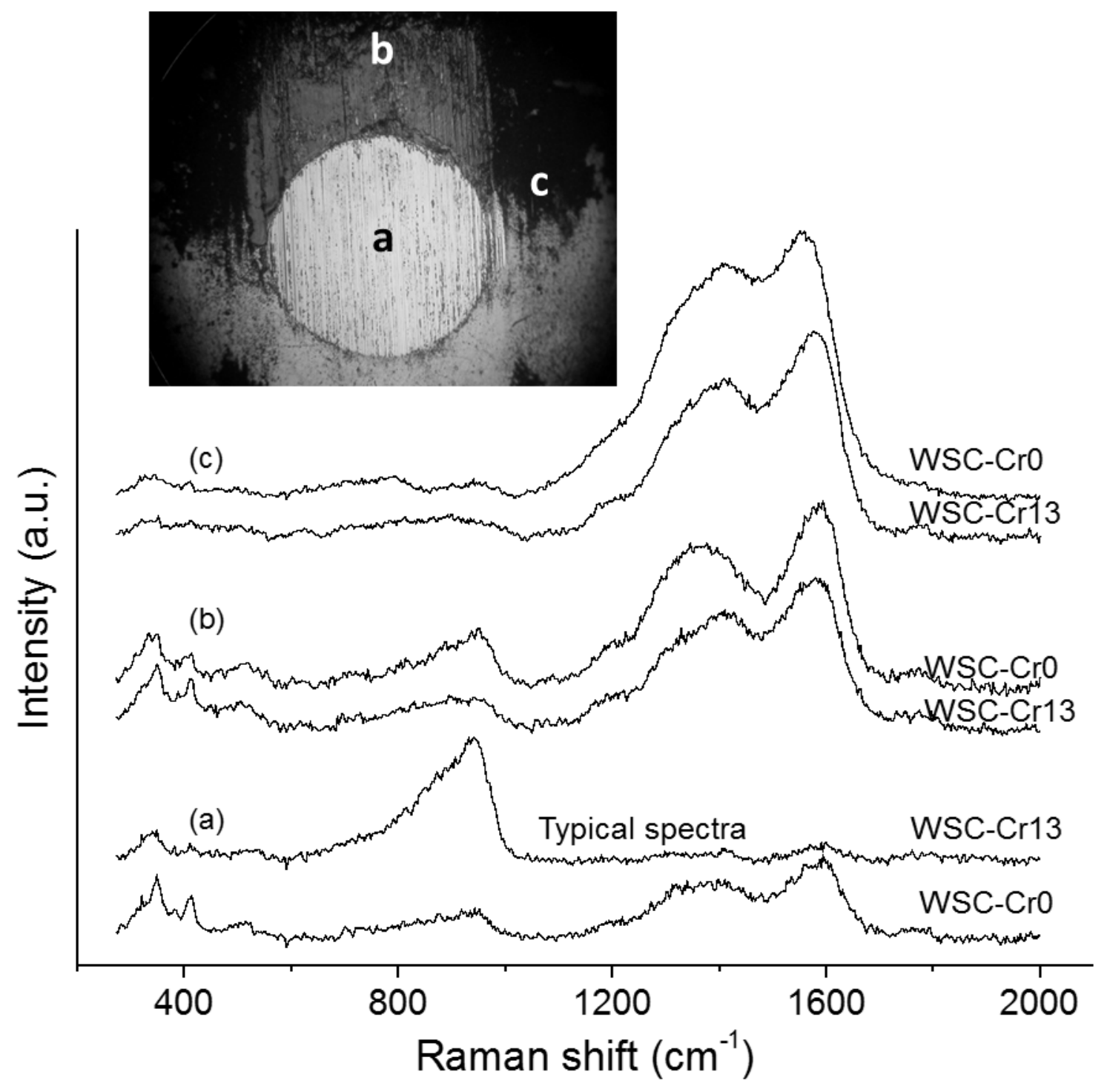

Fig 8 Raman spectra taken from different part of the ball (see inset and text).

A TEM cross-section sample of the tribofilm on a ball that was tested against WSC-Cr7 coating in humid air was prepared by FIB; the position of FIB cut is shown in Fig. 7. The tribofilm was very thin (about $20 \mathrm{~nm}$ ) and amorphous-like, a except for some stripes of $\mathrm{WS}_{2}$ (Fig. 9). Elemental mapping showed mainly oxygen and iron (Fig 7), although the low thickness of the tribolayer limited more detailed chemical analysis. Nevertheless, the results are consistent with those of Raman spectroscopy. 

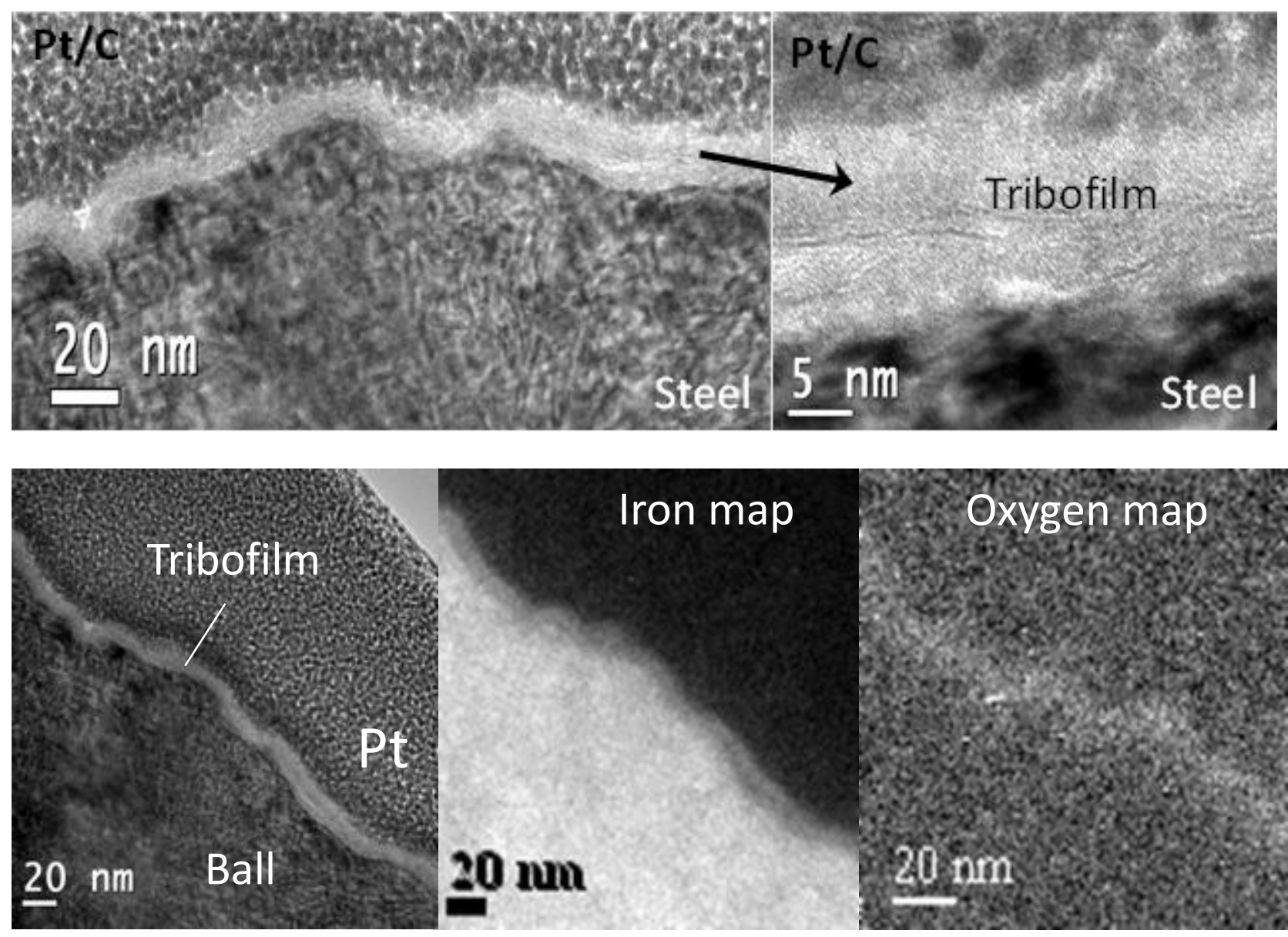

Fig. 9 TEM cross-section of the tribolayer on the worn ball surface (upper rod and lower left) and Fe and $\mathrm{O}$ maps of the area (lower middle and right).

The wear tracks on the coated samples were investigated by SEM/EDS, TEM, XPS and Raman spectroscopy. The TEM cross section micrograph of the WSC-Cr7 coating shown in Fig. 10 revealed a relatively thick tribolayer, which was significantly different from the as-deposited coating. It was mostly amorphous with only small areas showing crystalline phases, where particularly $\mathrm{WS}_{2}$ platelets were identified. There was no indication of $\mathrm{WS}_{2}$ phase at the outermost surface of the tribolayer. However, a thin layer of $\mathrm{WS}_{2}$ with basal planes parallel to the surface (002 orientation) was found on the interface between the coating and the tribolayer. The chemistry of the tribolayer was analyzed with EELS and EDS and showed high oxygen content together with iron and tungsten (Fig. 11). The concentration of sulfur and carbon was significantly lower in the tribolayer than in the coating below. 


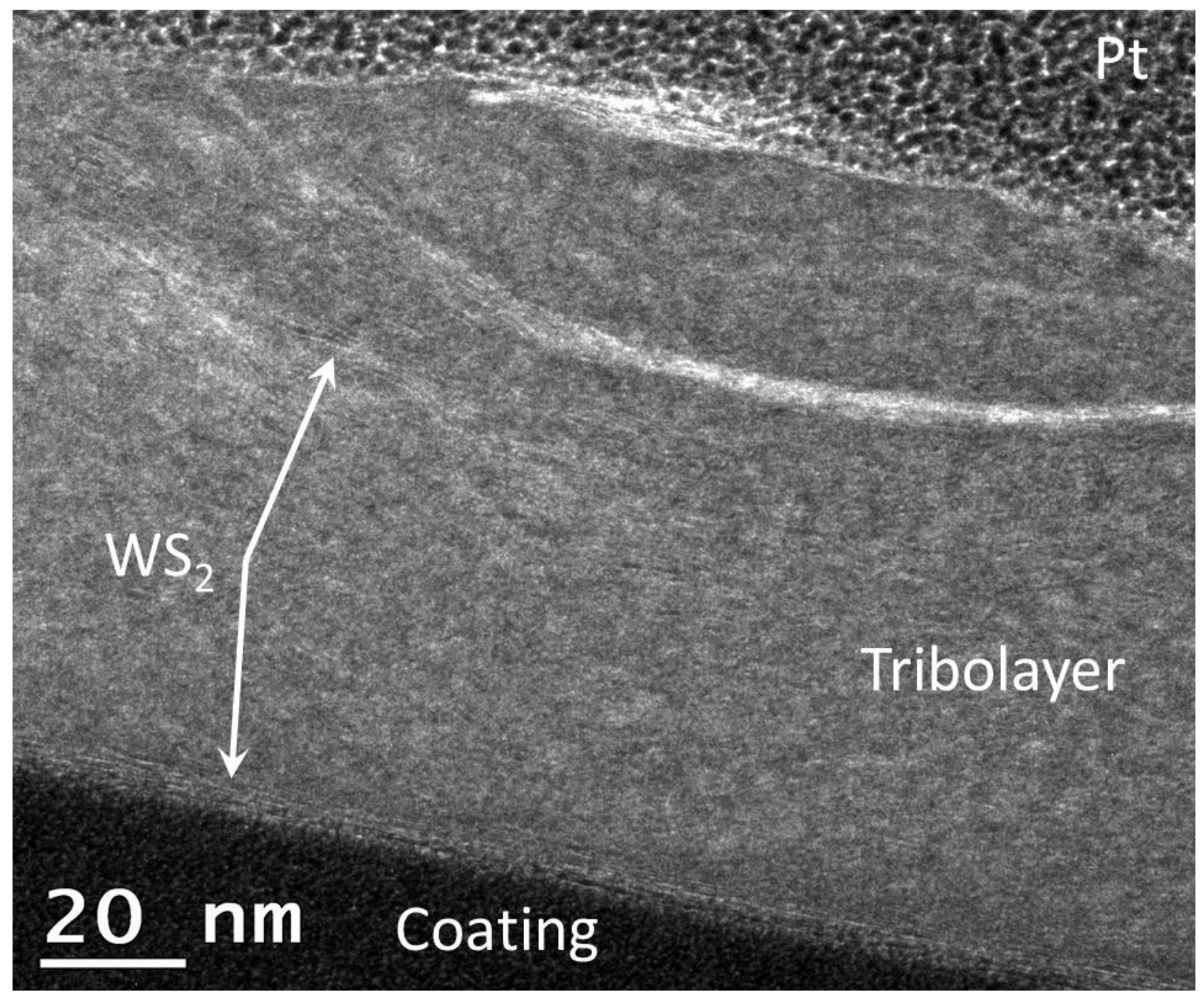

Fig. 10 TEM cross-section of the surface zone of the wear track, WSC-Cr7 coating, sliding test in humid air. 


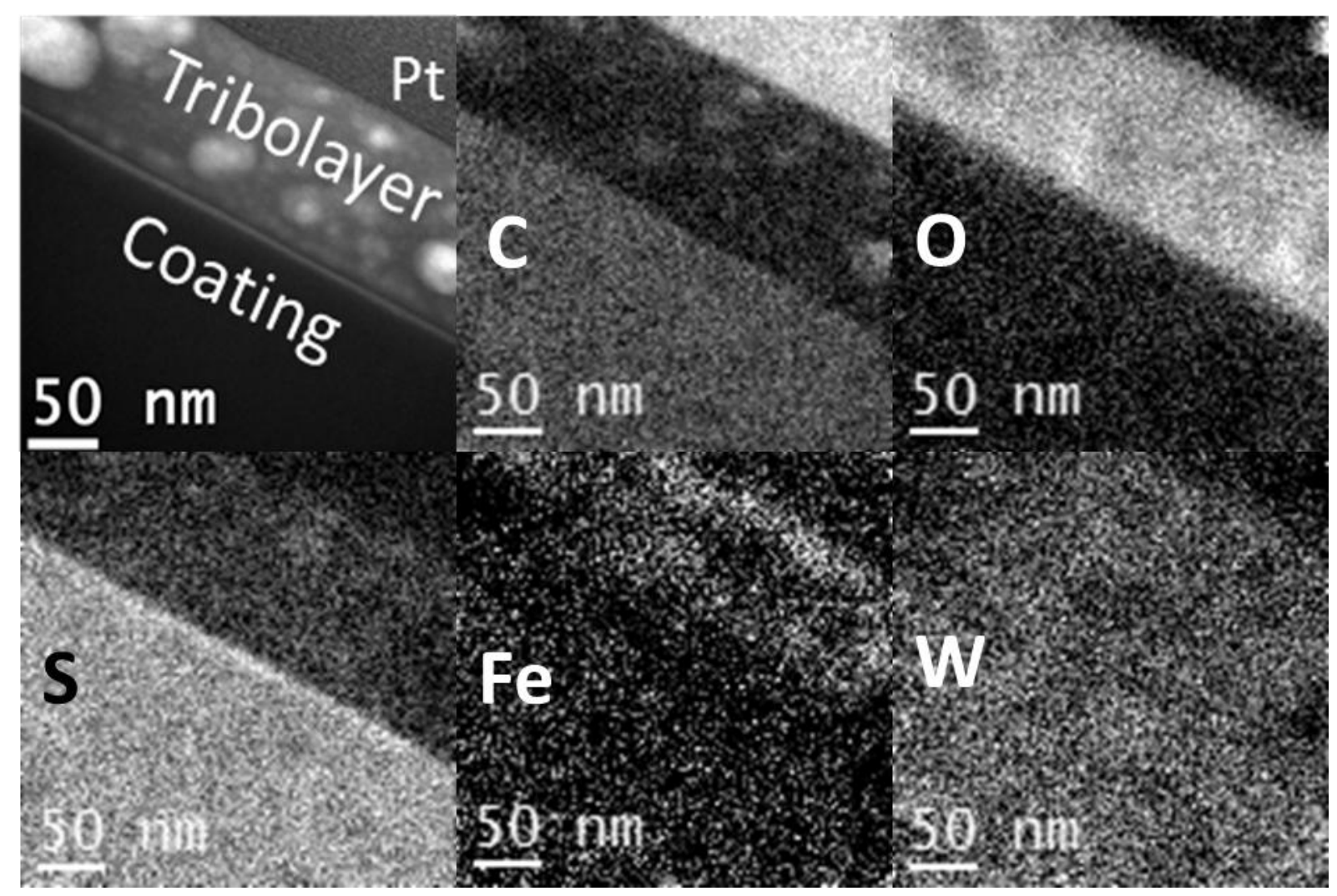

Fig 11 EFTEM elemental mapping of the tribolayer, WSC-Cr7 coating. Note that the different maps are not quantitatively comparable.

\subsubsection{Sliding in dry air}

After the sliding tests in dry air, the tribofilm formed on the ball consisted of a thick layer accumulated in front of the wear scar and a thinner layer covering major parts of the scar. Contrasting to the tests in humid air, the material adhered on the ball seems to be chemically homogeneous. No higher concentration of carbon or $\mathrm{WS}_{2}$ (Fig. 12) were observed. One part of scar is not covered (or only covered by a very thin layer). This part was probably not in contact with the coating and hence not participating in the sliding process. 

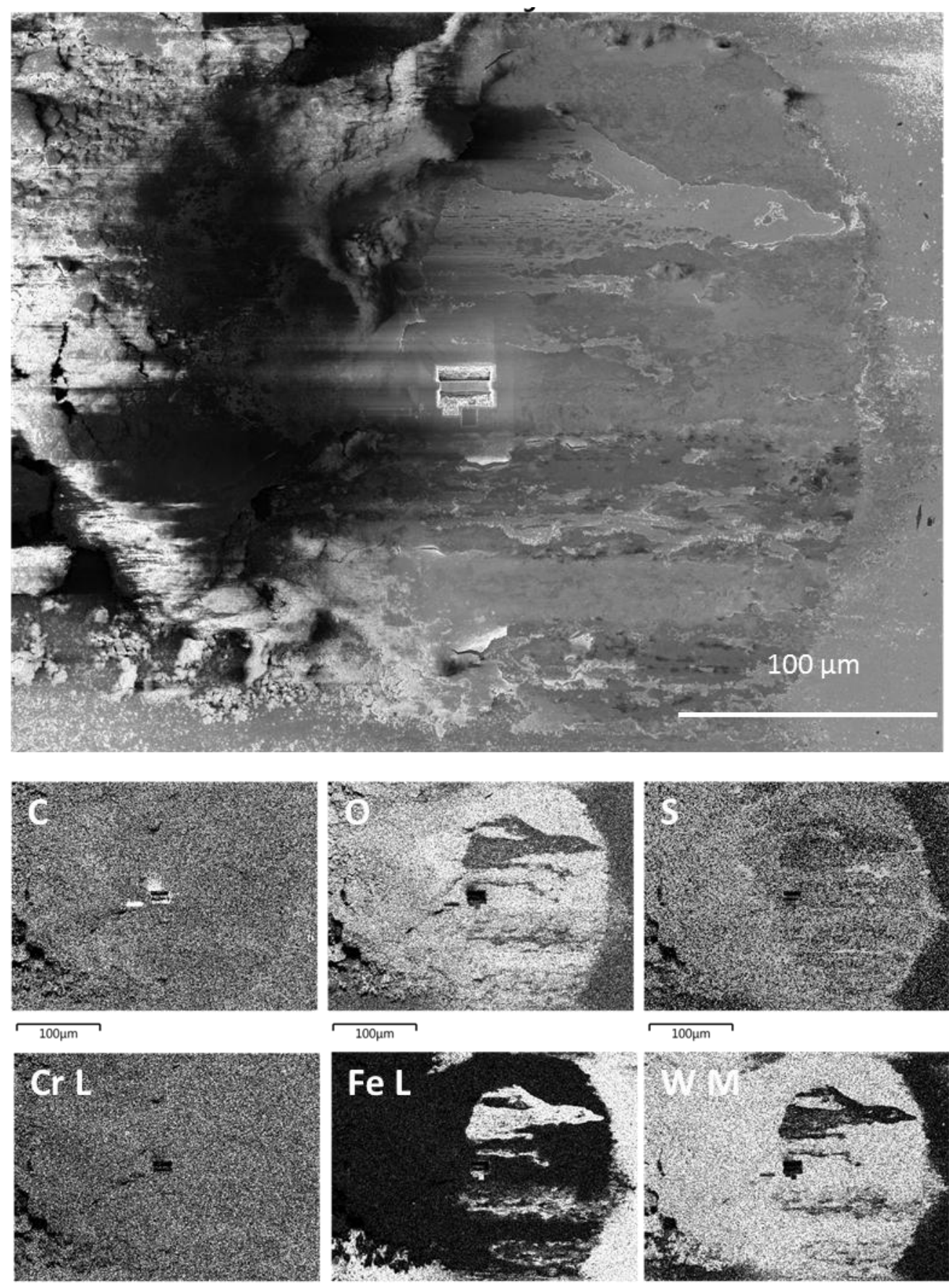

$\longdiv { 1 0 0 \mu \mathrm { m } }$

$100 \mu \mathrm{m}$

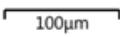

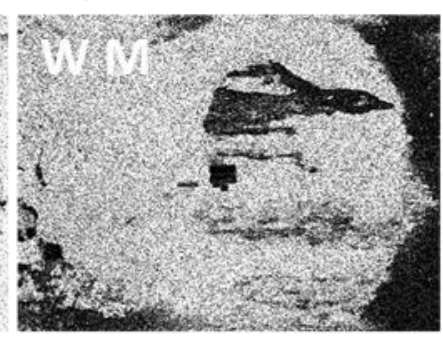

$\longdiv { 1 0 0 \mu \mathrm { m } }$

Fig. 12 SEM micrograph and EDS elemental mapping of the wear scar on the ball after a sliding test against the WSC-Cr7 coating with $10 \mathrm{~N}$ load in humid air. Note the position of FIB cut from the preparation of the TEM cross-section sample.

TEM investigation of the tribofilm cross-section showed several cracks and voids (Fig. 13). However, the upper part of the tribofilm was dense and showed a distinct, (002) oriented $\mathrm{WS}_{2}$ layer 
on top of an amorphous-like layer. The $\mathrm{WS}_{2}$ layer was 4 to10 molecular layers thick and seems to be covering the entire tribofilm surface (Fig. 13). Nanocrystalline tungsten oxide was observed below $\mathrm{WS}_{2}$ layer; however, it is probably only measurement artifact since the amorphous tungsten oxide could be easily crystallized under electron beam.

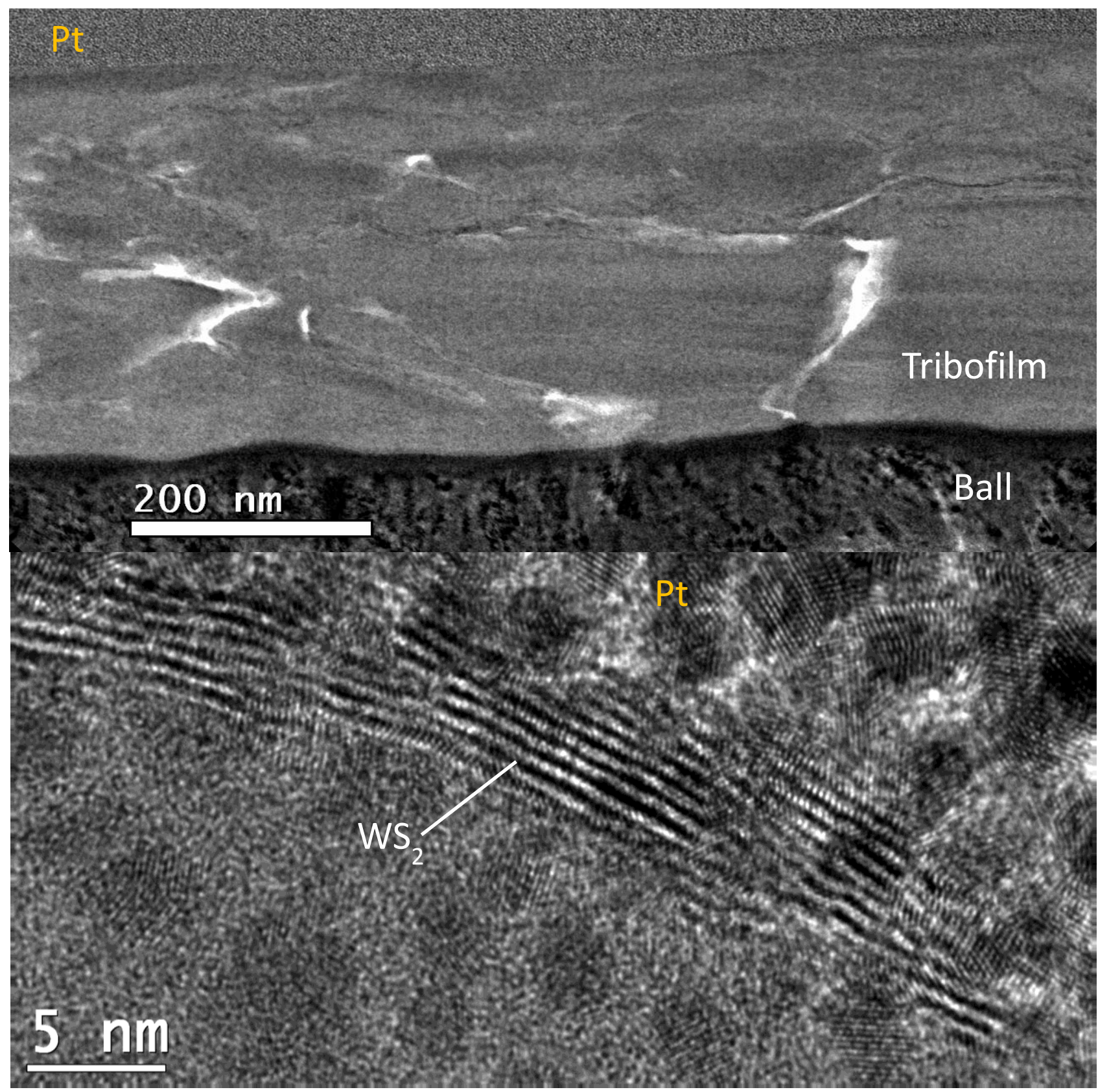

Fig 13. TEM cross-section of the tribofilm on the ball tested against the WSC-Cr07 coating in dry air. Overview (top), and close-up (bottom) showing that the outermost $5 \mathrm{~nm}$ of the tribofilm has a well-ordered $\mathrm{WS}_{2}$ layer. 
The tribofilm in the wear track on the coating had a thickness of approximately $40 \mathrm{~nm}$ and consisted of two clearly separated layers (both roughly $20 \mathrm{~nm}$ thick - see Fig. 14). The upper layer, closest to the interface, was identified as $\mathrm{WS}_{2}$ with basal planes oriented parallel to the surface. The lower layer was amorphous-like and EELS spectra indicated chromium oxides. Also, it showed much lower carbon content in the tribofilm film than in the coating below.

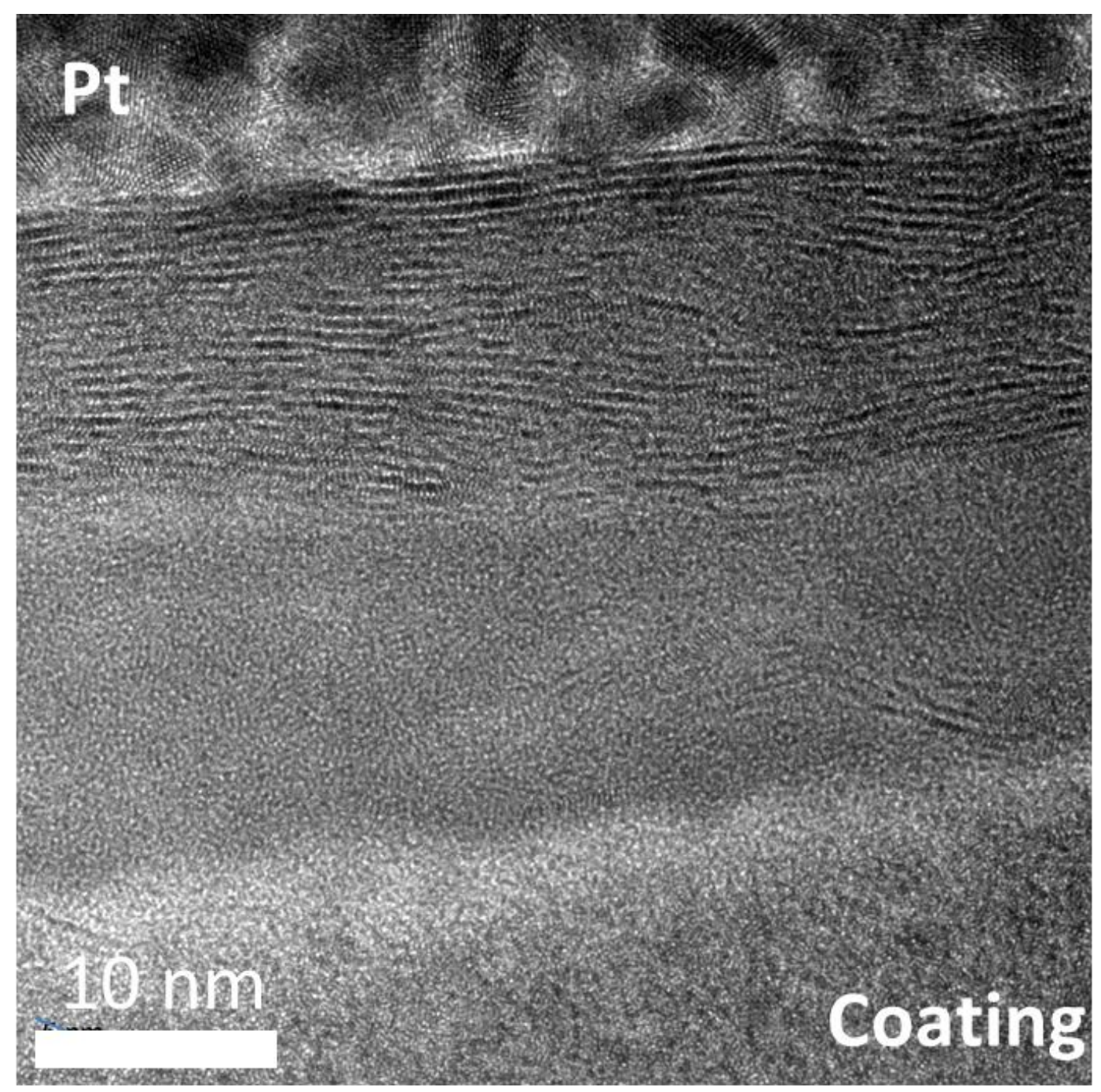

Fig. 14 TEM cross-section of the tribolayer formed in the wear track of WSC-Cr7 tested against a steel ball in dry atmosphere, load $10 \mathrm{~N}$. 
Raman spectra from the wear track surface of WSC-Cr07 coating are shown in Fig. 15. The sharp peak at $420 \mathrm{~cm}^{-1}$ confirmed the presence of well-ordered and relatively thick $\mathrm{WS}_{2}$ layer. It was difficult to distinguish $\mathrm{WS}_{2} \mathrm{E}_{2 \mathrm{~g}}\left(356 \mathrm{~cm}^{-1}\right)$ peak and $\mathrm{Cr}_{2} \mathrm{O}_{3}$ positioned at $350 \mathrm{~cm}^{-1}$; however, the shape of the peak in such position, particularly its high intensity/FWHM ratio, was typical for crystalline $\mathrm{WS}_{2}$. The Raman spectra in the wear track thus significantly differ from those obtained after sliding in humid air (Fig. 15).

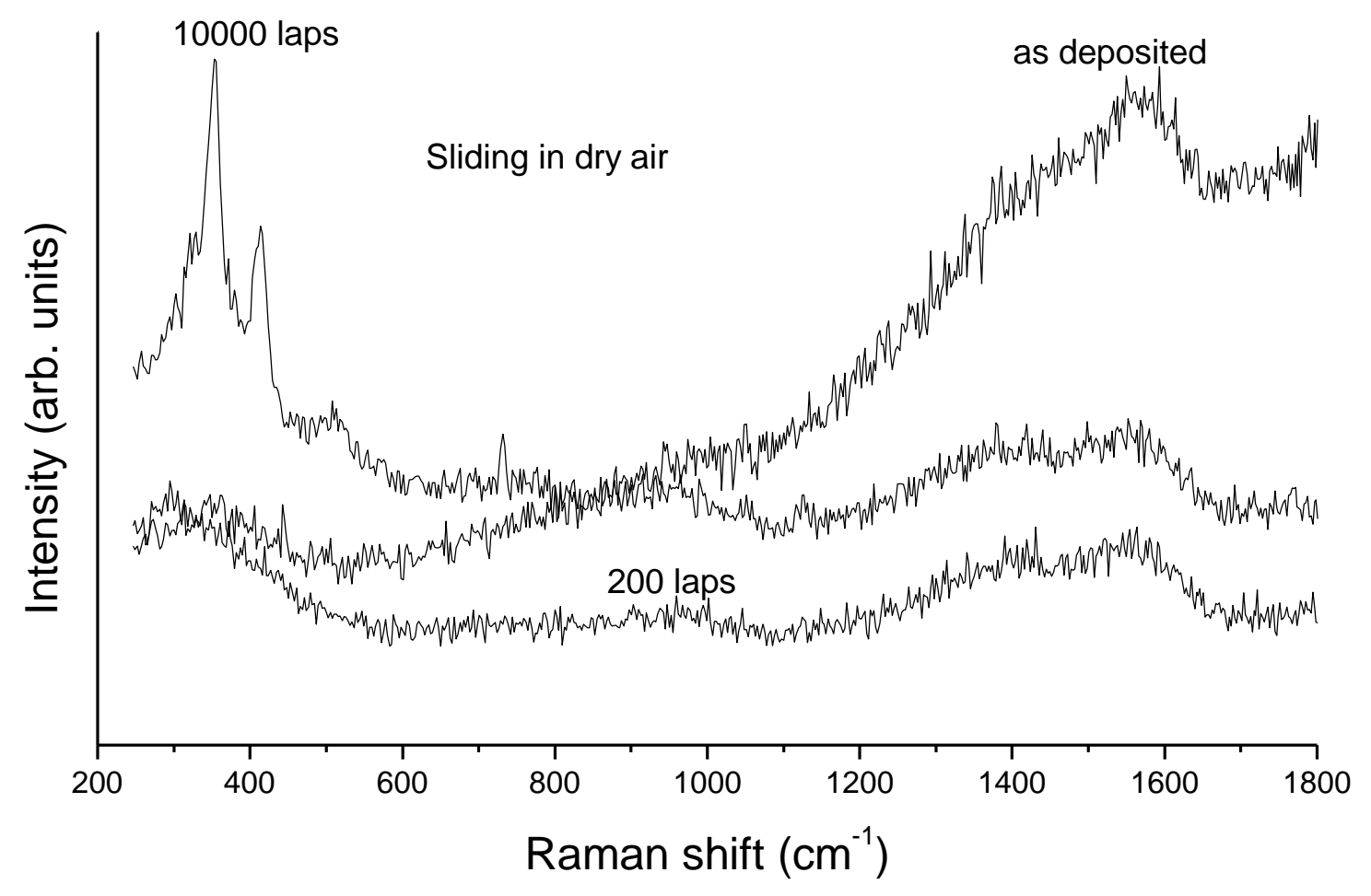




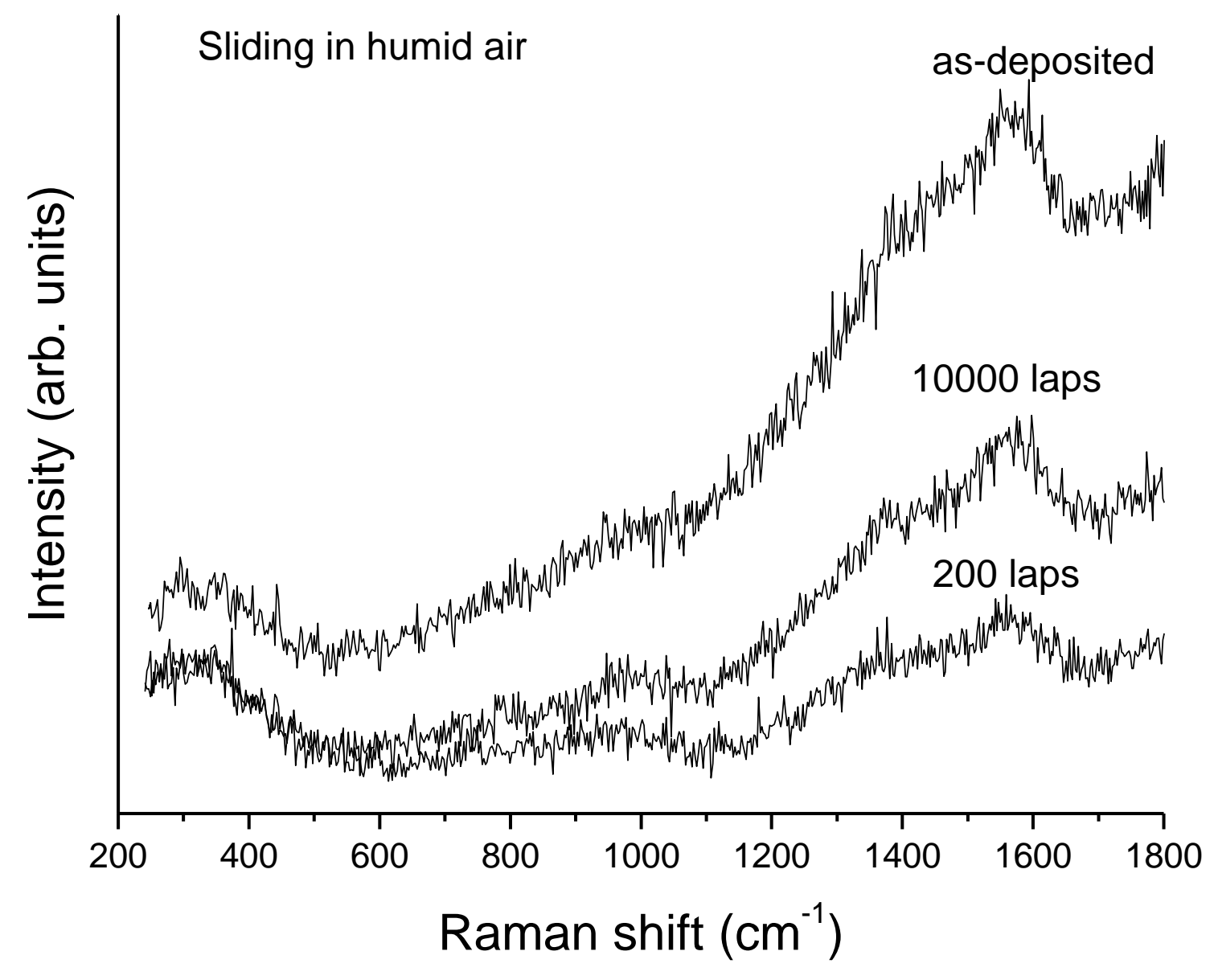

Fig. 15 Raman spectra of as-deposited WSC-Cr07 coating and of the center of the wear tracks after 200 and 10000 cycles, sliding in dry (upper) and humid (lower) air.

\section{Discussion}

The core objective of this study was to identify the effect of alloying WSC coating with chromium on the structure, mechanical and tribological properties. There are several reports dealing with thin films based on TMD alloyed with metals, such as (Ti [6,7,27], Al [28], Au [29,30], Pb [31], Ni [32,33], Cr [34,35]); the effects of doping metal on the coating structure, density, or mechanical properties are well studied. However, the role of doping metal in the tribological contact remains unknown. Improved tribological properties of metal-doped TMD coatings are often attributed to 
reactions of the metals with residual atmosphere in the deposition chamber, particularly with oxygen. As a consequence, the composition of dichalcogenides is closer to ideal stoichiometry, which is known to be beneficial to reduce friction [1]. It has been speculated that the metal (namely titanium [6]) preferentially oxidizes in the contact and protects the sensitive TMD phase (oxidation and/or corrosion leads to strong bonding between basal planes). However, in a recent detailed contact analysis of a $\mathrm{WS}_{2}$-Ti system no such behavior was found [7].

Doping of the pure TMD typically resulted in a hardness increase of about one order of magnitude higher and an increase in the density of the films, which are important factors contributing to friction reduction. To distinguish the indirect effect of improved mechanical properties and the role of metal at the sliding interface is very challenging. Wahl et al. [31] prepared amorphous Pb-Mo-S film and observed a thin $\mathrm{MoS}_{2}$ tribolayer (1-2 molecular layers) at the coating sliding interface and relatively thick $\mathrm{MoS}_{2}$ tribofilm adhered on the ball surface (pin-on-disc test) suggesting that $\mathrm{Pb}$ played only limited role in the sliding process. Chromik et al. investigated complex nanocomposite $\mathrm{YSZ} / \mathrm{Au} / \mathrm{MoS}_{2} / \mathrm{C}$ coatings (YSZ - yttria-stabilized zirconia) showing that low friction was related to the formation of $\mathrm{MoS}_{2}$-rich tribolayer [36]. Our recent results summarized in [11] show that, in the case of TMD-C films, the TMD tribolayer is exclusively formed in the contact area, whereas carbon is immediately removed.

In this study, chromium in as-deposited films is not bonded to oxygen, which is preferentially bonded to tungsten (see XPS results above); thus, the gettering effect of chromium during the deposition process was limited. Alloying with chromium increased the hardness and improved the coating adhesion, although not dramatically. We have shown in our previous studies on TMD-C systems that hardness higher than $4 \mathrm{GPa}$ is sufficient to support the low-friction behaviour [11].

Nevertheless, co-sputtering with chromium significantly changes the film microstructure. In the absence of $\mathrm{Cr}$ (WSC-CrO), the coating is nanostructured with separated $\mathrm{WS}_{2}$ platelets embedded into a carbon matrix, while it becomes amorphous-like when the $\mathrm{Cr}$ content is 7 at.\%. Different nanostructure could be an important factor in the formation of a tribolayer on the coating surface 
and material transfer to the ball surface (tribofilm). Fig. 9 and Fig. 11 indicate the presence of iron in both tribolayer and tribofilm (sliding in humid air); considering the oxygen content in the tribolayer, it is highly probable that iron is fully oxidized. The presence of iron originating from the ball is interesting. Wear of the ball occurs mainly at the initial stage of the sliding, when the contact pressure is the highest (note high friction coefficients during running in). The size of the wear scar on the ball is almost identical after 50000 cycles and after 5000 cycles. In other words, the ball wear is very limited in the steady state regime. We expect that the ball surface becomes oxidized in the contact and that iron oxide then becomes embedded into the tribolayer on the coating surface. Such mechanical intermixing might hinder the formation of a self-lubricant $\mathrm{WS}_{2}$ layer at the interface.

We have demonstrated that the wear track surface of the WSC film is covered almost exclusively by a thin $\mathrm{WS}_{2}$ layer [10]; Cr-containing WSC coatings show mainly oxides at the interface and consequently exhibit higher friction coefficients.

The very low friction coefficient when sliding in dry air suggests formation of well-ordered $\mathrm{WS}_{2}$. Indeed, $\mathrm{WS}_{2}$ layers were found on both sides of the contact interface, i.e. on the top of the wear track and the bottom of the tribofilm adhered to the ball. Interestingly, a layer consisting mostly of chromium oxide was found between $\mathrm{WS}_{2}$ top layer and the coating. The worn surfaces analyzed were sampled long time after the friction coefficient had stabilized and thus in the steady-state regime. Chromium oxide could be formed during running in, but progressive wear (obviously there is wear during the steady-state, although very low) would eventually wear oxide layer off, if it is not replenished. How could the chromium oxide retain its position between the unchanged (or almost unchanged) coating and the top $\mathrm{WS}_{2}$ layer? And how is the top low-friction layer replenished, when it is separated from the coating by a layer of chromium/tungsten oxide?

We cannot answer these complex questions based on our experimental results; nevertheless, we can present a hypothesis based on a relatively simple model developed by Rigney et al. [37]. They used molecular dynamics to simulate the sliding between two amorphous surfaces with different hardness and elastic moduli. They showed that sliding led to mechanical intermixing, which could 
be at least partially responsible for the development of a nanocrystalline material in the contact. They applied this model to a similar self-lubricant system, nanocomposite $\mathrm{WC} / \mathrm{DLC} / \mathrm{WS}_{2}$ coating [38], and analyzed possible intermixing in the sliding interface. Both tribolayer on the wear tracks and the tribofilm on the ball observed in our case (dry air) consisted of two well separated layers, $\mathrm{WS}_{2}$ and oxide. We can expect that $\mathrm{WS}_{2}$ has lower shear resistance than the oxide layer and the latter lower shear resistance than ball material or unaltered coating. The sliding interface is then in the $\mathrm{WS}_{2}$ layer, as expected. When the $\mathrm{WS}_{2}$ top layer is worn out (i.e. mechanically removed from the contact area), the sliding interface moves to the softer material (in our case the oxide layer) and the oxide is mechanically mixed with the coating material. $\mathrm{WS}_{2}$ is then transported to the contact and the well-ordered low-friction layer is formed again on the surface. Further study will be aimed at MD simulations of such layer to investigate this hypothesis.

Finally, we will comment the decrease of the friction coefficient with increased applied load, typical feature of pure TMD coatings. This behaviour is often approximated by the formula integrating the shear stress of solids at high pressures and the Hertzian model for contact pressure $[39,40,41,42]$ :

$\mu=\tau_{0} \cdot \pi \cdot\left(\frac{3 \mathrm{R}}{4 \mathrm{E}}\right)^{\frac{2}{3}} \mathrm{~L}^{-\frac{1}{3}}+\alpha$,

where $\mathrm{R}$ is the radius of the ball, $\mathrm{L}$ is the normal load, $\tau_{0}$ is the interfacial shear strength, $\alpha$ is a material constant representing the adhesive forces at zero load and E' is the composite modulus of the sliding couple. Our investigation clearly demonstrates that this approximation cannot be used in the case of doped TMD films and very probably not also for pure TMD coatings. Formation of a tribofilm on the ball, together with initial wear of both ball and coating, significantly increases the contact area and thus decreases the contact pressure; thus, ideal Hertz contact gives unrealistic high pressures. Structural transformation in the contact leads to different elastic moduli of the materials involved; therefore, composite modulus calculated from bulk materials cannot be used. Considering the presented results and our previous studies [11,43], we suggest that higher contact pressure facilitates both the tribolayer formation on the coating surface and the transfer of coating material to 
the ball. Moreover, well-oriented platelets of low-friction $\mathrm{WS}_{2}$ could be formed at the interface. As a consequence, the friction will decrease with increasing load.

\section{Conclusions}

Microstructure of WSC self-lubricant film with $\mathrm{WS}_{2}$ platelets embedded in carbon matrix became amorphous when the film was co-sputtered with chromium. Hardness and adhesion increased linearly with chromium content from approx. 5 (WSC) to $7 \mathrm{GPa}(13$ at.\% of $\mathrm{Cr}$ ). Chromium was mostly in metallic form; chromium carbides were not observed. Compared to WSC, the friction and the wear rate of Cr-doped films were higher. The coatings showed a very low friction in dry air attributed to the formation of a $\mathrm{WS}_{2}$ layer at the sliding interface. Such low-friction layer was not observed when the sliding tests were carried out in humid air. Alloying of WSC film with chromium deteriorated the tribological properties of non-doped WSC coating.

\section{Acknowledgements}

This work was supported by the Czech Science Foundation through the project 108/10/0218.

\section{References}

[1] A.R. Lansdown, Molybdenum Disulphide Lubrication, Elsevier, 1999

[2] A. Erdemir, J.-M. Martin, Editors, Superlubricity, Elsevier, 2007

[3] A. Erdemir, C. Donnet, Tribology of Diamond-like Carbon Films: Fundamentals and Applications, Springer-Verlag New York, 2007

[4] J. Moser, F. Levy, F. Bussy, Composition and growth mode of $\mathrm{MoS}_{\mathrm{x}}$ sputtered films, J. Vac. Sci. Technol. A 12 (1994) 494

[5] T. Kubart, T. Polcar, L. Kopecký, R. Novák, D. Nováková, Surf. Coat. Technol. 193 (2005) 230

[6] D. G. Teer, New solid lubricant coatings, Wear 251 (2001) 1068.

[7] T.W. Scharf, A. Rajendran, R. Banerjee, F. Sequeda, Growth, structure and friction behavior of 
titanium doped tungsten disulphide (Ti-WS(2)) nanocomposite thin films, Thin Solid Films 517 (2009) 5666

[8] A.A. Voevodin, J.P. O'Neill, J.S. Zabinski, Nanocomposite tribological coatings for aerospace applications, Surf. Coat. Technol. 116-119 (1999) 36-45

[9] A. Nossa, A. Cavaleiro, Chemical and physical characterization of C(N)-doped W-S sputtered films, J. Mater. Res. 19 (2004) 2356

[10] T. Polcar, M. Evaristo, A. Cavaleiro, Self-lubricating W-S-C nanocomposite coatings, Plasma Process. Polym. 6 (2009) 417-424

[11] T. Polcar, A. Cavaleiro, Review on self-lubricant transition metal dichalcogenide nanocomposite coatings alloyed with carbon, Surf. Coat. Technol. 206 (2011) 686-695 [12] W.C. Oliver and G.M. Pharr, An improved technique for determining hardness and elastic modulus using load and displacement sensing indentation experiments, J. Mater. Res. 7 (1992) 1564.

[13] L.E. Rumaner, T. Tazawa, F.S. Ohuchi, Compositional change of (0001) WS2 surfaces induced by ion beam bombardment with energies between 100 and $1500 \mathrm{eV}$, J. Vac. Sci. Technol. A 12(4), 1994, 2451

[14] C.D. Wagner, W.H. Riggs, C.E. David, J.F. Moulder, and G.E. Muilenberg in: Handbook of Xray photoelectron spectroscopy, Perkin-Elmer Corporation, 1979.

[15] Masaoki Oku, Shigeru Suzuki, Naofumi Ohtsu, Toetsu Shishido, Kazuaki Wagatsuma, Comparison of intrinsic zero-energy loss and Shirley-type background corrected profiles of XPS spectra for quantitative surface analysis: Study of Cr, Mn and Fe oxides, Appl. Surf. Sci. 254 (2008) 5141-5148.

[16] T. Polcar, M. Evaristo, A. Cavaleiro, Friction of self-lubricating W-S-C sputtered coatings sliding under increasing load, Plasma Process. Polym. 4 (2007) S541-S546

[17] P. Hoffman, H. Galindo, G. Zambrano, C. Rincón, P. Prieto, FTIR studies of tungsten carbide in bulk material and thin film samples, Mater. Charact. 50 (2003) 255-259 
[18] B.-H. Xu, B.-Z. Lin, Z.-J. Chen, X.-L. Li, Q.-Q. Wang, Preparation and electrical conductivity of polypyrrole/WS 2 layered nanocomposites, J. Colloid Interf. Sci. 330 (2009) 220-226

[19] B. Adamczyk, O. Boese, N. Weiher, S.L.M. Schroeder, E. Kemnitz, Fluorine modified chromium oxide and its impact on heterogeneously catalyzed fluorination reactions, J. Fluorine Chem. 101 (2000) 239-246

[20] D. Adliene, J. Laurikaitiene, V. Kopustinskas, S. Meskinis, V. Sablinskas, Radiation induced changes in amorphous hydrogenated DLC films, Mat. Sci.Eng. B - Adv. 152 (2008) 91-95

[21] J.Álvarez-Garsía, J. Marcos-Ruzafa, A. Pérez-Rodríguez, A. Romano-Rodríguez, J.R. Morante, R. Scheer, Thin Solid Films 361-362 (2000) 208.

[22] M. Bouchard, D.C. Smith, C. Carabatos-Nédelec, An investigation of the feasibility of applying Raman microscopy for exploring stained glass, Spectrochimica Acta Part A 68 (2007) 1101-1113

[23] J.E. Maslar, W.S. Hurst, W.J. Bowers Jr., J.H. Hendricks, M.I. Aquino, I. Levin, In situ Raman spectroscopic investigation of chromium surfaces under hydrothermal conditions, Appl. Surf. Sci. 180 (2001) 102-118

[24] P.M. Sousa, A.J. Silvestre, N. Popovici and O. Conde, Morphological and structural characterization of CrO2/Cr2O3 films grown by Laser-CVD, Appl. Surf. Sci. 247 (2005) 423-428 [25] A.C. Ferrari, J. Robertson, Interpretation of Raman spectra of disordered and amorphous carbon, Phys. Rev. B 61 (2000) 14095.

[26] V. Rigato, G. Maggioni, D. Boscarino, G. Mariotto, E. Bontempi, A.H.S. Jones, D. Camino, D. Teer, C. Santini, Ion beam analysis and Raman characterisation of coatings deposited by cosputtering carbon and chromium in a closed field unbalanced magnetron sputter ion plating system, Surf. Coat. Technol. 116-119 (1999) 580

[27] A. Savan, M.C. Simmonds, Y. Huang, C.P. Constable, S. Creasey, Y. Gerbig, H. Haefke, D.B. Lewis, Effects of temperature on the chemistry and tribology of co-sputtered $\mathrm{MoS}_{\mathrm{x}}$-Ti composite thin films, Thin Solid Films 489 (2005) 137. 
[28] J.D. Holbery, E. Pflueger, A. Savan, Y. Gerbig, Q. Luo, D.B. Lewis, W.-D. Munz, Alloying MoS2 with Al and Au: structure and tribological performance, Surf. Coat. Technol. 169-170 (2003) 716.

[29] S. Mikhailov, A. Savan, E. Pflueger, L. Knoblauch, R. Hauert, M. Simmonds, H. Van Swygenhoven, Morphology and tribological properties of metal (oxide)- $\mathrm{MoS}_{2}$ nanostructured multilayer coatings, Surf. Coat. Technol. 105 (1998) 175.

[30] J.R. Lince, Tribology of co-sputtered nanocomposite $\mathrm{Au} / \mathrm{MoS}_{2}$ solid lubricant films over a wide contact stress range, Trib. Lett. 17 (2004) 419.

[31] K.J. Wahl, D.N. Dunn, I.L. Singer, Wear behavior of Pb-Mo-S solid lubricating coatings, Wear 230 (1999) 175.

[32] J.R. Lince, M.R. Hilton, A.S. Bommannavar, Metal incororporation in sputter-deposited $\mathrm{MoS}_{2}$ films studied by EXAFS, J. Mater. Res. 10 (1995) 2091

[33] M.R. Hilton, G. Jayaram, L.D. Marks, Microstructure of cosputter-deposited metal- and oxide$\mathrm{MoS}_{2}$ solid lubricant thin films, J. Mater. Res. 13 (1998) 1022.

[34] Y.L. Su, W.H. Kao, Tribological behaviour and wear mechanism of $\mathrm{MoS}_{2}-\mathrm{Cr}$ coatings sliding against various counterbody, Tribol. Int. 36 (2003) 11.

[35] M.C. Simmonds, A. Savan, E. Pfluger, H. Van Swygenhoven, Mechanical and tribological performance of $\mathrm{MoS}_{2}$ co-sputtered composites, Surf. Coat. Technol. 126 (2000) 15.

[36] C.C. Baker, R.R. Chromik, K.J. Wahl, J.J. Hu, A.A. Voevodin, Preparation of chameleon coatings for space and ambient environments, Thin Solid Films 515 (2007) 6737.

[37] D.A. Rigney, S. Karthikeyan, The Evolution of Tribomaterial During Sliding: A Brief Introduction, Tribol. Lett. 39 (2010) 3

[38] J.-H. Wu, D. A. Rigney, M. L. Falk, J. H. Sanders, A. A. Voevodin and J. S. Zabinski, Tribological behavior of WC/DLC/WS 2 nanocomposite coatings, Surf. Coat. Technol. 188-189 (2004) 605

[39] B. J. Briscoe, A. C. Smith, The interfacial shear strengths of molybdenum disulphide and 
graphite films, ASLE Trans., 25 (1982) 349

[40] I. L. Singer, R. N. Bolster, J. Wegand, S. Fayeulle, B. C. Stupp, Hertzian stress contribution to low friction behavior of thin MoS2 coatings, Appl. Phys. Lett. 1990, 57, 995

[41] J. L. Grosseau-Poussard, P. Moine, M. Brendle, Shear strength measurements of parallel MoSx thin films, Thin Solid Films, 307 (1997) 163

[42] T.W. Scharf, S.V. Prasad, M.T. Dugger, P.G. Kotula, R.S. Goeke, R.K. Grubbs, Growth, structure, and tribological behavior of atomic layer-deposited tungsten disulphide solid lubricant coatings with applications to MEMS, Acta Mater 54 (2006) 4731

[43] T. Polcar, M. Evaristo, R. Colaço, C. S. Sandu, A. Cavaleiro, Nanoscale triboactivity: The response of Mo-Se-C coatings to sliding, Acta Mater 56 (2008) 5101 